\title{
Fractional Order PID Controller for Minimizing Frequency Deviation in a Single and Multi-area Power System with Physical Constraints
}

\author{
Ahmed Mohammed Saba \\ Department of Computer Engineering, Ahmadu Bello University Zaria, Nigeria \\ Email: msahmed5050@gmail.com
}

\begin{abstract}
In this paper, a Fractional Order PID (FOPID) controller to minimize frequency deviation in a single and two area power system is presented. Minimizing high frequency deviation in the presence of physical constraints is very paramount in load frequency control. This is because large frequency deviation can cause the transmission line to be overloaded which may damage equipment's at the generating and distribution level. In this paper, power system with Communication Delay, Governor Dead Band and Generation Rate Constraint were considered and modeled appropriately. An anti-windup scheme was employed to limit the effects of these physical constraints on the power system. The proposed FOPID was designed using the Fractional Order Modeling and Control toolbox available in MATLAB/Simulink. Antlion Optimization algorithm was used to optimize the gains of the FOPID controller by minimizing Integral Square Error as the objective function. The Integral Square Error to be minimized is the summation of the errors in frequency deviation, tie-line power deviation and the area control error. Simulations were first conducted on power systems designed without physical constraints, and results obtained outperformed other designed methods available in literature for one and two area power systems. Three physical constraints were then added to the power system. The proposed methods outperformed other designed method in minimizing frequency deviation, tie-line power deviation and area control errors. However, the proposed FOPID controller took a longer time to balance the generated power and load demand when compared to other designed methods for power systems without physical constraints.
\end{abstract}

Keywords - fractional order PID controller (FOPID); Antlion optimization; load frequency control $(\mathrm{LCF})$; generation rate constraint (GRC); governor dead band (GDB) and time delay

\section{INTRODUCTION}

Electric power system can be defined as networks, which consist of generation, transmission and distribution of electrical energy. Power system control can be seen as maintaining a balance between electrical power generation and load demand. The two control loops in power system are the secondary and primary control loops [1]. The turbinegovernor system within the plant is used to realize the primary control where only reactive power is balanced [2]. Hence, in an interconnected system, the primary control is not enough because of the steady-state frequency error due to reactive power balance in the primary control loop [4-8]. Since frequency deviation must be minimized in all areas of interconnected power systems. Another level of power balance called supplementary control is introduced within a large-scale (multi-area) power system [9]. Power system control can be categorized into two: the first part relates to frequency or active power balance while the second part is related to voltage regulation or reactive power balance $[10$, 11]. The reactive power plus voltage control is generally known as Automatic Voltage Regulator [12]. The active power plus Load Frequency Control (LFC) is also known as Automatic Load Frequency Control (ALFC) [13]. To maintain stability when there exist variation in transmission line power flow and the active power demand, Automatic Load Frequency Control (ALFC) is required. [14].

One of the problems in large scale power system may be due to imbalance between generated power, load demand and system losses in the load frequency control [15-19]. The process of maintaining balance between load demand and generated power together with scheduled transmission line power exchange and system losses is referred to as Load Frequency Control (LFC) [20-22]. Some conventional LFC uses an integral controller whose dynamic performance is restricted by integral gain [41]. A high integral gain can impair the performance of a system causing longer oscillations [42].

Fractional Order Proportional Integral Derivative (FOPID) Controller is expressed by fractional-order differential equation where the fractional part of the integral and derivative can be a positive integer or zero [32]. Control system response can be improved when the integral and derivative of a PID controller are expanded into fractional order [36,39]. Fractional Order Modeling and Control (FOMCON) toolbox build based on the concept of fractional order calculus was designed to enhance research centered on fractional order system [38].

The major idea of load frequency control in a physical system is to minimized large frequency deviation. Several kinds of research have been conducted on the area of load frequency control with and without physical constraints. A PID controller based on Linear Matrix Inequality (LMI) for a single and multi-area power system was proposed by [1]. A new PID controller for interconnected power systems via Direct Synthesis (DS) method was investigated by [4]. The effects of GDB was investigated by [7] using Redox Flow Batteries (RFB) together with Unified Power Flow Controller (UPFC) to improve LFC of a multi-source interconnected power system. A controller for LFC of power systems for 
single and multi-area cases was presented by [33], Laurent Series was used to obtain the gain of the PID controller by expanding controller transfer function. A FOPID controller to minimize the deviation in frequency of a single-area power system considering non-reheat, hydro and reheat turbines was investigated in [39]. The effects of GRC and GDB nonlinearities on LFC of power systems with reheat, nonreheat and hydro turbines was investigated in [41 - 45], and an anti-windup scheme was added to the designed power system to retain the performance and stability of the system.

Particle Swarm Optimization (PSO) was used to optimize the gains of the FOPID controller for LFC of two-area nonreheat thermal power systems in [12]. The effects of GRC were investigated in [13] where differential evolution algorithm was used to optimize the fractional integral term and integer-order Propositional and Derivative gain to minimize frequency deviation in a three-area power system. The effects of non-reheat and reheat turbines in a two-area power system with physical constraints such as GDB, time delay and GRC were investigated by [16], an integral controller optimized using genetic algorithm was used to minimize the deviation in frequency. Load frequency control of power system using FOPID based on Big Bang Big Crunch (BB-BC) optimization algorithm and IMC scheme had been presented by [21]. An optimized FOPID and a Tilted Integral Derivative with Filter (TIDF) controller for a two-area multisource power system were presented by [27]. Parameters of PID, TIDF and FOPID controller were obtained using the Differential Evolution algorithm. A PI controller optimized using the Antlion algorithm to minimize deviation in frequency of three-area power system was presented by [35].

Large frequency deviation in power system can cause the transmission line to be overloaded which may damage equipment at the distribution level and the mechanical devices at the generation unit. In power system, frequency deviation is to be minimized at all times to maintain the balance between the generated power and load demand. This is difficult to attain because of differences in load demand of each area. Large frequency deviation normally occurs when the differences in load demand and the generated power is high and also when physical constraints such as GRC, GDB and time delay occurs within the system. As such, the performance of the load frequency controller is degraded even for a small load perturbation. However, when physical constraints such as GDB, GRC and time delay are added to any power system designed, the system dynamics becomes non-linear thereby making it difficult to minimize frequency deviation even with a robust load frequency controller [45]. Several kinds of research have been conducted on minimizing the frequency deviation of a power system designed with multiple physical constraints [15]. Yet the system suffers from large frequency deviation and longer settling time due to the effects of these physical constraints [45]. Some works have been done by researchers to minimize the effects of one physical constraint by using an anti-windup control in the design of the power system [45]. Results obtained show that the effects of the physical constraint were minimized by the anti-windup control. In this regard, this paper is aimed at designing a single and two area power system with multiple physical constraints such as governor dead band, generation rate constraints and time delay being considered simultaneously. The effects of the GDB and GRC will be minimized by adding an anti-windup scheme for each constraint. These constraints occur in all physical power systems, as such, to study the dynamic behavior of a real power system; it is required to incorporate GDB, time delay and GRC into the designed power system. Ignoring these constraints for easier analysis leads to results that can risk the system's integrity and security [45].

In this paper, a Fractional Order Proportional Integral Derivative (FOPID) controller to minimize the effects of physical constraints on an interconnected power system will be presented. The physical constraints include: Generation Rate Constraints (GRC), Governor Dead Band (GDB) and time delay. An anti-wind up scheme will be employed to minimize the effects of GRC and GDB. The gain of the proposed controller will be optimized using the Antlion algorithm. The efficiency of the proposed method will be verified in terms of frequency deviation, tie-line power deviation, area control error and settling time by applying a load disturbance to the system. The Robust performance will also be verified by parametric variation. The efficiency of the proposed method will further be verified by applying a random load and ramp rate varying load to the system. Results obtained are expected to show an improvement in terms of frequency deviation, Area Control Error (ACE) of each area and the tie-line power deviation of the connected areas when compared to other design methods available in literatures. Such methods include: Proportional Integral Derivative controller based on Linear Matrix Inequality Singh et al. [1], Proportional Integral Derivative controller based on Direct Synthesis approach Anwar \& Pan [4] as well as Internal Model Control (IMC) based Proportional Integral Derivative controller Tan [42] for load frequency control

The rest of the paper is organized as follows. The system modeling and description will be given in section II. The description of the Fractional Order PID controller and the anti-windup control will be given in section III. Methodology and the description of the optimization algorithm will be given in section IV. Simulations, results and discussions will be given in section $\mathrm{V}$, summary, conclusion and further works will be discussed in section VI.

\section{POWER SYSTEM MODELING AND DESCRIPTION}

Power system configuration for load frequency control will be discussed in this section. A single-area thermal power system has three major components viz. governor, turbine and a generator. The supplementary/secondary control loop is used to return the frequency to its nominal value [24]. The block diagram of a single-area power system network is shown in Fig. 1.

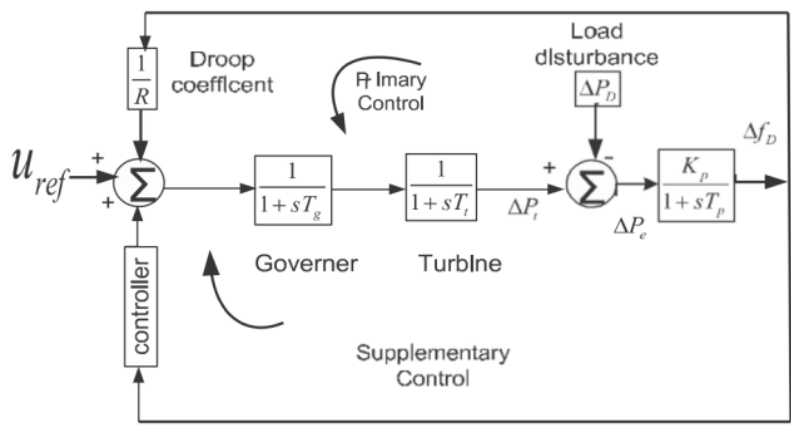

Fig. 1. Block Diagram for a Single-Area Power System. Singh et al. [1] 


\section{A. Turbines}

Turbines are used for converting energy obtained from steam and water into mechanical energy that can be fed into the generator [34]. Turbines can be classified into three: the hydraulic turbine which works with water flow, non-reheat and reheat turbines. Each of these turbines can be modeled by a transfer function. Reheat turbines are represented by secondorder units whereas non-reheat turbines can be modeled by first-order units [30, 31]. For this paper, a non-reheat and reheat turbine will be considered. The transfer function of a non-reheat turbine is given in (1)

$$
\frac{\Delta P_{T}(\mathrm{~s})}{\Delta P_{V}(\mathrm{~s})}=\frac{1}{1+s T_{T}}
$$

where $\Delta P_{V}(s)$ represents the turbine input, $\Delta P_{T}(s)$ is the turbine output and $T_{T}$ is the turbine time constant. (2)

The transfer function for reheat turbine is represented by

$$
G_{T_{-} R}=\frac{C T_{r} s+1}{\left(\mathrm{~T}_{r} \mathrm{~s}+1\right)\left(\mathrm{T}_{t} \mathrm{~s}+1\right)}
$$

where $T_{r}$ is a constant and $C$ represents the fraction of the total generated power by the reheat process.

\section{B. Generators}

Generators are devices that convert mechanical energy from the turbine into electrical energy [23]. The generator's transfer function is given by (3)

$$
G_{p}(\mathrm{~s})=\frac{K_{p}}{1+s T_{p}}
$$

where $G_{p}$ represents the generated power, $K p$ represents the electric system gain and $T_{p}$ is the electric system time constant

\section{Governors}

Governors (speed limiter or controller) are devices used to measure and regulate the speed of a machine i.e. they maintain the stability of the turbine or speed of the generator [28]. The governor changes the turbine input if it senses the deviation in frequency due to variation in load [23]. The transfer function of the governor is given in (4)

$$
\frac{\Delta P_{v}(\mathrm{~s})}{\Delta P_{g}(\mathrm{~s})}=\frac{1}{1+s T_{g}}
$$

where $\Delta P_{V}(s)$ represents the output from the generator, $\Delta P_{g}(s)$ indicates input to the generator and $T_{g}$ is the time constant of the governor.

\section{Tie-Lines}

Tie-line (transmission line) is used in power system to connect an area to its neighboring area thereby allowing the exchange of power between these areas.

A multi-area power system comprises of at least two areas that are linked together by transmission lines. Each area within the system has three inputs i.e. $\Delta P_{r e f}$ which is denoted as $U_{r e f}, \Delta P_{D}$ which is the load disturbance in the area and $\Delta P_{\text {tie }}$ which represents the transmission line power error [4]. Fig. 2 shows the block diagram of a multi-area power system network for control area i.

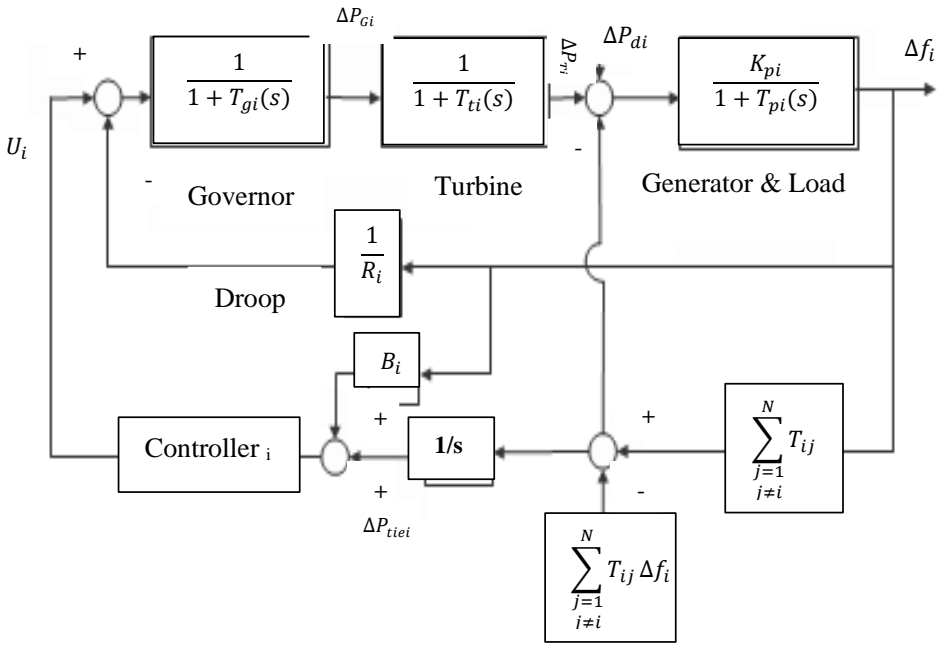

Fig. 2. The Block Diagram of Control Area i.

\section{E. Area Control Error}

Area Control Error (ACE) can be seen as the differences between scheduled and actual generated power within an area taking into account the frequency bias factor [24]. The ACE of an area is used in LFC to maintain the frequency of that area very close to the defined values and the tie-line power exchange very close to its scheduled value. When the ACE of an area is zero, the frequency deviation and the tie-line power of that area will also be set to zero [13]. Area control error can be mathematically modeled by (5)

$$
A C E=\sum_{k+1}^{k} P_{k}-P_{s}+B\left(f_{\text {act }}-f_{0}\right) M W
$$

where $P_{k}$ represents the tie-line power, $P_{S}$ is the scheduled power exchange, $f_{0}$ is the base frequency, $f_{a c t}$ is the actual frequency and $B$ is the frequency bias coefficient.

When the ACE is negative, it indicates that the power flow out of an area is either very small or there is drop in frequency or both as such the generation has to be increased [42].

\section{F. Governor Dead-Band (GDB)}

Governor Dead Band (neutral zone) can be defined as an interval of a signal band where no action occurs as seen in Fig. 3. Governor Dead Band is used in voltage regulation to prevent continuous sinusoidal oscillation. This oscillation can be caused by excessive valve response, valve overlaps in hydraulic relays and backlash (gears with slope/loose gears) particularly when mechanical backlash eliminator is not available [7]. When an input signal is changed, the speed governor cannot immediately respond, but wait until the input signal reaches a particular value [47].

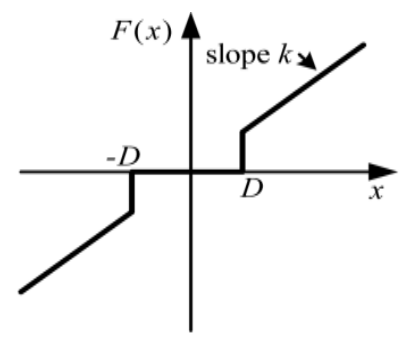

Fig. 3. Governor Dead Band

Dead band can be classified into two: intentional and unintentional dead-bands [45]. The unintentional dead band is 
unavoidable and can be caused by loose gears or sticky valves. The intentional governor dead band is employed to control turbine mechanical wear or excessive controller activities in modern governor design [7].

\section{G. Generation Rate Constraints}

Generation Rate Constraints (GRC) is employed in the thermal generating unit to limit the speed at which the output power changes as shown in Fig. 4. When the thermal generating unit changes its output power rapidly, the turbine will go through mechanical and thermal stress which could reduce its lifespan [20,29].

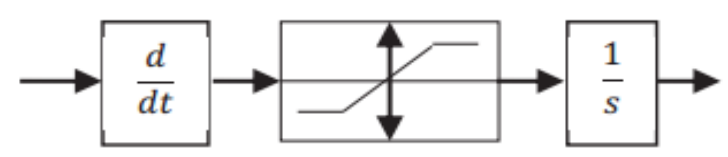

Fig. 4. The GRC Model for Thermal Unit

Generation rate constraints can be considered in the turbine by adding a limiter which can be used to restrict the rate at which the valve opens or closes [45]. For this study, a $10 \%$ GRC, given as 0.0017 p.u.MW/sec will be considered for a non-reheat thermal system.

\section{H. Communication Delay}

Communication delay is the time delay within the system which can occur in two communication link. The first one is between the measured frequency through the Remote Terminal Unit (RTU) and the control center while the second one is between the output of the control center and the individual generating unit [37]. For easy analysis, communication delay can be represented by $s e^{-s \tau}$, where $\tau$ is the estimated delay time.

\section{DESCRIPTION OF FOPID AND ANTI-WINDUP CONTROL}

\section{A. Fractional Calculus and FOPID $\left(P I^{\lambda} D^{\mu}\right)$ Controller}

The FOPID controller is an extension of the PID controller with additional fractional integral and derivative choices [3]. The FOPID transfer function is given in (6).

$$
C(\mathrm{~s})=\mathrm{K}_{p}+\left(\frac{K_{i}}{s^{\lambda}}\right)+K_{d} s^{\mu}
$$

Where the proportional gain is represented by $K_{p}$, the integral gain is represented by $K_{i}$ is, $K_{d}$ is the derivative gain, $\mu$ is the fractional part of the Derivative gain and $\lambda$ represents the fractional part of the integral gain.

The FOPID controller has five tuning parameters i.e. the PID controller gains $K_{p}, K_{i}$ and $K_{d}$ and the fractional part of the integral and derivative gain $\lambda$, and $\mu$ respectively. The PID controllers are specific 5 cases of the FOPID controller. When $\lambda=\mu=1$, an Integer Order PID controller is obtained. When $\lambda=\mu=0$, an integer order promotional controller is obtained. when $\lambda=0$ and $\mu=1$, an Integer Order promotional derivative controller is obtained, and for $\lambda=1$ and $\mu=0$, an Integer Order proportional-integral controller is obtained. Fig. 5 shows different configurations of IOPID and FOPID controller as $\lambda$ and $\mu$ changes.

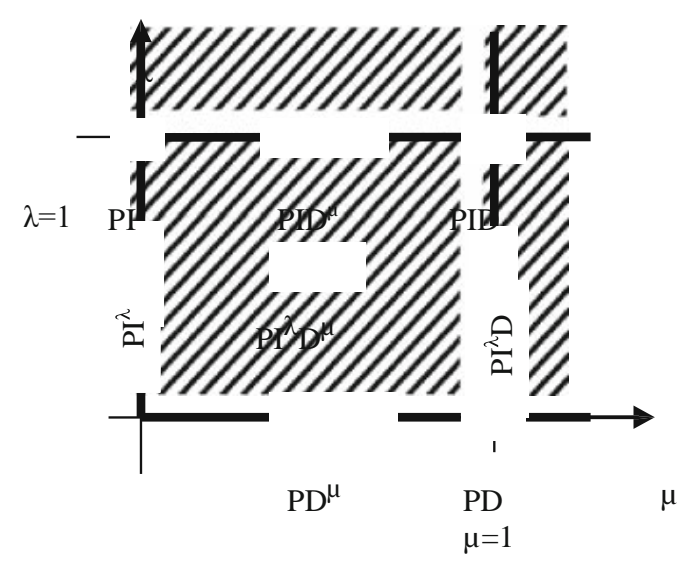

Fig. 5. Illustration of Fractional and Integer Order Controllers. Alomoush [2]

Since the integer-order PID controller has two fewer tuning parameters than the FOPID, the FOPID controller gives a better chance to design a more robust controller than the IOPID controller particularly when a fractional system is to be controlled [25,47]. The structure of the FOPID controller is given in Fig. 6.

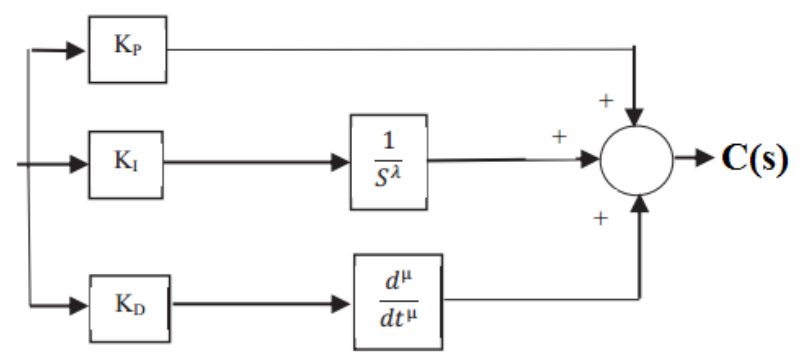

Fig. 6. FOPID Controller

\section{B. Anti-windup Control}

An anti-windup scheme is a means of preventing an integral term from accumulation above or below a predetermined bound [45]. It is employed to ensure stability whenever a feedback control loop is open by saturation [45]. For the anti-windup of GRC, the error between the realistic and the ideal output of the turbine is fed back into the integral of the PID controller as shown in Fig. 7. For the anti-windup of GDB, the error between the realistic and the ideal output of the governor is fed back and added to the output of the PID controller as shown in Fig. 8.

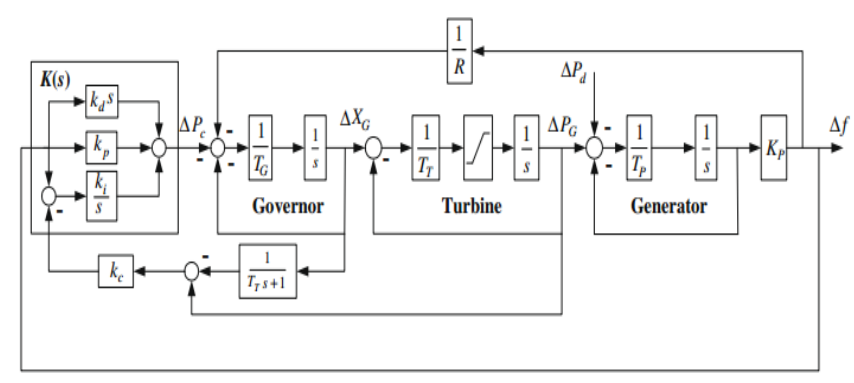

Fig.7. Anti-windup Scheme for Generation Rate Constraints. Tan [41] 


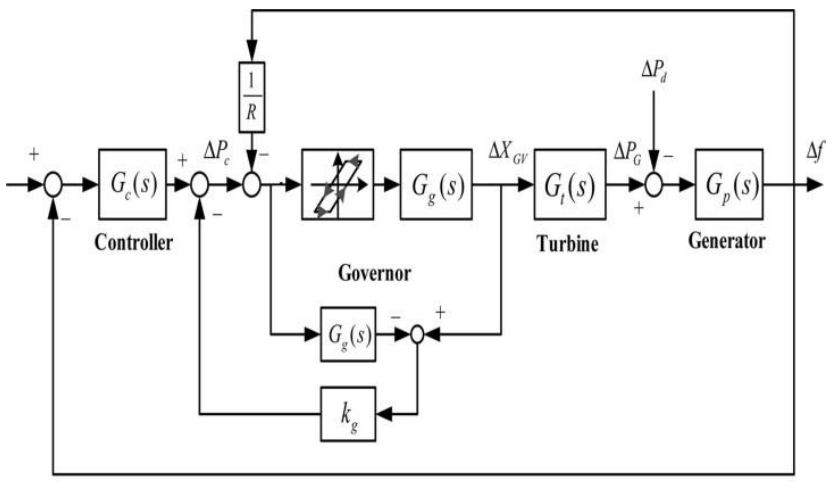

Fig. 8. Anti-windup Scheme for Governor Dead Band

\section{Methodology AND ANTLION OptimizATION ALGORITHM}

\section{A. Antlion Algorithm}

Antlion Optimization Algorithm (ALO) mimics interactions between Antlions and Ants in a trap [26]. To model such interactions, Ants are required to move over the search space, and Antlions are allowed to hunt them and become fitter using traps [35]. The Antlion digs a coneshaped pit in the sand by moving along a circular path and throwing out sands with its massive jaw [26]. Different coneshaped pits dogged by the Antlion are shown in Fig. 9.

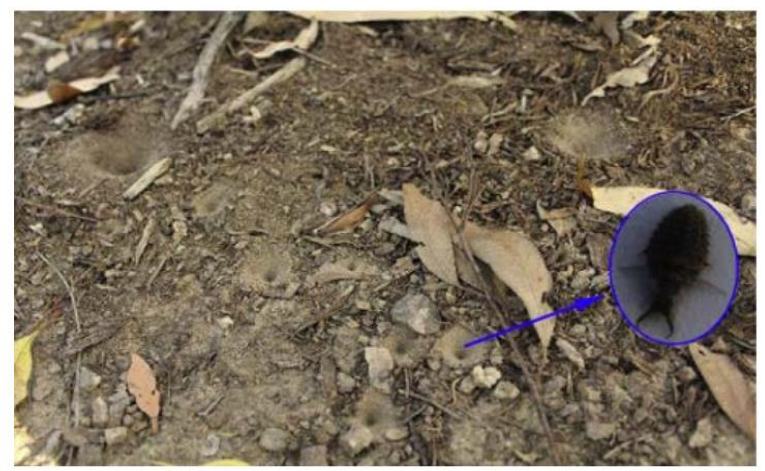

Fig. 9. Different Sizes of Cone-Shaped Pits. Mirjalili [26]

After digging the trap, the Antlion hides beneath the bottom of the cone and waits for insects (preferably Ant) to be trapped in the pit as illustrated in Fig.10 [26].

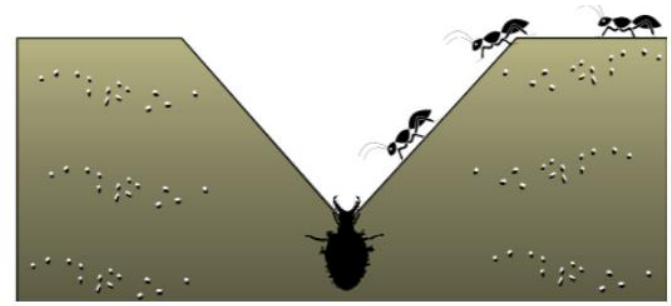

Fig. 10. Antlion Positioned at the Bottom of the Cone. Mirjalili [26]

To have the Ants trapped in the pit, the edges of the trap are made sharp and the slopes very steep. The Antlion immediately tries to catch any Ant that falls into the trap. When the prey (Ants) tries to escape from the Antlion (Predator) pit, the Antlion intelligently throws sand to the edges of the pit using its jaws. This is done to draw the Ant back to the bottom of the pit [26]. The Antlion draws the Ant inside the soil and consumes the prey, the Antlion then throws out the remains and rebuilds the trap for the next catch.

\section{B. The Operators in ALO Algorithm}

Ants search for food by moving randomly, such movements can be modeled using (7) [26].

$$
X(\mathrm{t})=\left[0, \operatorname{cs}\left(2 r\left(t_{1}\right)-1\right), \operatorname{cs}\left(2 r\left(t_{2}\right)-1\right), \ldots, \operatorname{cs}\left(2 r\left(t_{n}\right)-1\right)\right]
$$

The cumulative sum is represented by $c s$, the maximum number of iterations is represented by $\mathrm{n}, t$ represents step of random walk and $r(t)$ represents random function given in (8)

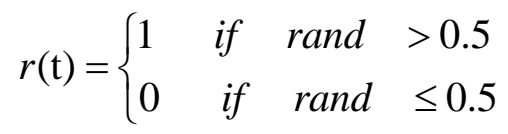

where rand is a random number generated with uniform distribution in the interval of $[0,1]$

\section{Description of Random Walks by Ants}

Since Ant's update their location using random walk at each optimization step, it is required to keep the random walks within the search area, (9) will be used at each step of optimization for normalization [26]

$$
X_{n o r m}=\frac{\left(\mathrm{x}(\mathrm{t})-a_{i}\right) \times\left(d_{i}^{t}-c_{i}^{t}\right)}{\left(b_{i}^{t}-a_{i}\right)+c_{i}}
$$

where $X_{\text {norm }}$ represents the normalized random walk, the minimum random walk of $i$-th variable is represented by $a_{i}$, the maximum random walk of $i$ - $t h$ variable is represented by $d_{i}, \mathrm{x}(\mathrm{t})$ is the random walk of Ant, $c_{i}^{t}$ represents the minimum of $i$-th variable at $t$-th iteration, $d_{i}^{t}$ indicates the maximum of $i$-th variable at $t$-th iteration and $c_{i}$ is the minimum of the $i$-th variable. Equation (9) is used to guarantee all the stochastic movement of Ant inside the search space.

\section{Trapping prey in Antlion's Pits}

Ants walks randomly within the search space while the Antlion walk in a circular form inside its pit. The Antlion uses this circular movement to attract Ants to the trap. The scenario that describes the trapping of Ants within the Antlion's pit is influenced by the random movement of the Ant. This scenario is modeled using (10) and (11) [26]

$$
\begin{aligned}
& c_{j}^{t}=\text { Antlion }_{j}^{t}+c^{t} \\
& d_{j}^{t}=\text { Antlion }_{j}^{t}+d^{t}
\end{aligned}
$$

where the minimum variables at $t$-th iteration is represented by $c^{t}$, the vector including the maximum of all variables at $t$ th iteration is represented by $d^{t}$, the minimum variable for $j$ th Ant at $t$-th iteration is represented by $c_{j}^{t}$, the maximum variables for $j$-th Ant at $t$-th iteration is represented by $d_{j}^{t}$ and Antlion ${ }_{j}^{t}$ represents the position of the selected $j$-th Antlion at the $t$ - $t h$ iteration.

\section{E. Process of Sliding Ants towards the Antlion}

Antlion throw sand towards the middle of the trap as it realizes an Ant is inside the pit, such behavior prevents an Ant 
from escaping from the trap. To model this behavior mathematically, (12) and (13) are proposed [26].

$$
\begin{aligned}
c^{t} & =\frac{c^{t}}{I} \\
d^{t} & =\frac{d^{t}}{I}
\end{aligned}
$$

where $I$ represents a ratio, the minimum variable at $t$-th iteration is represented by $c^{t}$, the vector containing the maximum variables at $t$-th iteration is represented by $d^{t}$. From (12) and (13), $I=10^{w} \frac{t}{T}$, as $t$ stands for the current iteration, the maximum number of iterations is represented by $T$, and $w$ represents a constant defined by the current iteration.

\section{G. Process of catching the Prey in the trap and Re-building the trap}

To model the process by which Ant is pulled into the soil and consumed by Antlion when it tried to escape, it is assumed that the Antlion is fitter than the corresponding Ant. The Antlion needs to relocate to the position of the Ant being hunted which will give it a better chance of catching new Ants. Equation (14) is used to model such behavior [26].

$$
\text { Antlion }_{j}^{t}=\text { Ant }_{j}^{t} \quad \text { if } \quad\left(A n t_{j}^{t}\right)>f\left(\text { Antlion }_{j}^{t}\right)
$$

where $t$ is the current iteration, Antlion ${ }_{j}^{t}$ stands for the position of selected $j$-th Antlion at the $t$-th iteration, and $A n t_{j}^{t}$ represents the position of $j$-th Ant at $t$-th iteration.

\section{H. Elitism}

The phenomenon that described the characteristics of the evolutionary algorithm that enable it to retain the best solution(s) obtained at any stage of the optimization process is called Elitism [26]. For every scenario, the Antlion with the best fitness is noted and regarded as elite. The movement of all Ants during iterations is expected to be influenced by the elite. In this case, Antlion is expected to guide all Ants towards the promising region on the search space by moving randomly using roulette wheel and the elite. This behavior can be mathematically modeled using (15):

$$
A n t_{j}^{t}=\frac{R_{A}^{t}+R_{E}^{t}}{2}
$$

where $R_{A}^{t}$ represents the stochastic walk around the Antlion at the $t$-th iteration, $R_{E}^{t}$ represents random walk around the elite at $t$-th iteration and $A n t_{j}^{t}$ represents the position of $i$-th Ant at $t$-th iteration.

\section{Constraints}

This is the condition matching the decision variables; they limit the values of the decision variables [26]. For this paper, the constraints include; Governor Dead Band and Generation Rate Constraints which are given by (16) and (17)

$$
\begin{aligned}
& G R C_{\min } \leq G R C \leq G R C_{\max } \\
& G D B_{\min } \leq G D B \leq G D B_{\max }
\end{aligned}
$$

where $G R C_{\min }$ represents the minimum value of the generation rate constraint, $G R C_{\max }$ represents the maximum value of the generation rate constraint, $G D B_{\min }$ represents the minimum value of the governor dead band and $G D B_{\max }$ represents the minimum value of the governor dead band.

\section{J. Optimizing the gains of FOPID controller}

In this section, the gains of the Fractional Order PID controller will be optimized using the antlion algorithm. This will be done by linking the designed Simulink model to the Antlion algorithm using the "Sim" command. The objective function to be minimized for areas one and two is the Integral Square Error (ISE) given by (18) and (19).

$$
I S E=\int_{0}^{t}\left(\left(f_{1}\right)^{2}\right) d t
$$

Where $f_{1}$ represents the frequency deviation for area one and $t$ is the simulation time.

$$
I S E=\int_{0}^{t}\left(\left(f_{1}\right)^{2}+\left(f_{2}\right)^{2}+\left(P_{t 1}\right)^{2}+\left(\mathrm{ACE}_{1}\right)^{2}+\left(\mathrm{ACE}_{1}\right)^{2}\right) d t
$$

Where $f_{1}$ represent the frequency deviation for area one, $f_{2}$, represent the frequency deviation for area two, $A C E_{1}$ is the Area Control Error for area one, $A C E_{2}$ is the Area Control

\begin{tabular}{|c|c|}
\hline $\mathrm{S} / \mathrm{N}$ & Steps \\
\hline 1. & Initialize randomly the initial population of antlions and ants \\
\hline 2. & Compute the fitness of antlions and ants \\
\hline 3. & Locate the best antlions and consider it as the elite (determined \\
\hline 4. & 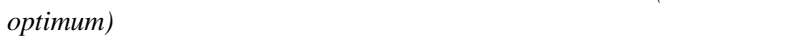 \\
\hline 5. & while the final last is not mollified \\
\hline 6. & for all ant \\
\hline 7. & Choose an antlion using Roulette wheel \\
\hline 8. & Update $c$ and $d$ using (12) and (13) \\
\hline 9. & Create and normalize random walk using (7) and (8) \\
\hline 10 . & Update the location of ant using (15) \\
\hline 11. & end for \\
\hline 12. & Compute all the ants fitness \\
\hline 13. & $\begin{array}{l}\text { Substitute an antlion with its equivalent ant when the ant becomes } \\
\text { fitter (14) }\end{array}$ \\
\hline 14. & Update elite if an antlion gets fitter than the elite \\
\hline 15. & $\begin{array}{l}\text { end while } \\
\text { Return elite }\end{array}$ \\
\hline
\end{tabular}
Error for area two, $P_{t 1}$ tie-line power deviation that link the two areas together and $t$ is the simulation time.

The errors that form the ISE to be minimized are frequency deviation, tie-line power deviation and area control error. An Antlion Optimization algorithm pseudocode is defined in Table 1.

\section{TABLE 1. PSEUDO CODES OF ALO ALGORITHM}

The simulation parameters in Table 2 are used to determine the optimal gain of the proposed FOPID controller. The lower bound (lb) and the upper bound (ub) varies depending on the gain of the FOPID controller to be optimized. When optimizing the fractional part of the controller i.e. lamda and mu ( $\lambda$ and $\mu$ ), the lower bound was set to 0.5 and the upper bound was set to be 1.1. However, when optimizing the gain of the integer part of the controller i.e. Proportional, Integral and Derivative (P I D), the lower bound was set to 0.1 and the upper bound was set to be 200 . The flowchart that describes the steps for optimizing the gains of the fractional order PID controller using the antlion optimization algorithm is given in Fig. 18.

Fig. 13, demonstrates how the ALO algorithm is linked to the power system designed to optimize the gain of the FOPID controller and the simulation parameter of the Antlion optimization algorithm is given in Table 2. 
TABle 2. ANTLION Optimization ALgORithm SimUlation PARAMETERS

\begin{tabular}{clcc}
\hline SN & \multicolumn{1}{c}{ Parameters } & Symbol & Value \\
\hline 1 & Number of search agents & SearchAgents_no & 250 \\
2 & Number of variables & Dim & 5 \\
3 & Maximum number of & Max_iteration & \\
& iterations & Lb & 100 \\
4 & Lower bound $(\mathrm{Kp}, \mathrm{Ki}, \mathrm{Kd})$ & $\mathrm{Ub}$ & 0.1 \\
5 & Upper bound $(\mathrm{Kp}, \mathrm{Ki}, \mathrm{Kd})$ & $\mathrm{lb}$ & 200 \\
6 & Lower bound $(\lambda, \mu)$ & $\mathrm{ub}$ & 0.5 \\
7 & Upper bound $(\lambda, \mu)$ & & 1.1 \\
\hline
\end{tabular}

\section{SimUlations, RESUlTS AND DisCUSSION.}

The power system was first designed without GRC, GDB and time delay for one and two area network. Due to the limitation of space, some figures are not plotted on this paper. Generation rate constraints, GDB and time delay were then added to a single and two area power systems. Parametric variation was used to verify the robust performance of the proposed method. Random load and Ramp rate varying load was also used to further verify the efficiency of the proposed method. The input signal for the Random load and Ramp rate varying load are given by Fig. 19 and Fig. 20.

\section{A. Simulations for one area power system without constraints}

The nominal system parameters of the non-reheat thermal power system in Fig. 14, are given as follows: $K_{p}=120$, $T_{p}=20, T_{t}=0.3, T_{g}=0.08, R=2.4$. A step change in load disturbance of 0.01 pu was applied to Fig. 14, at time $\mathrm{t}=$ $1 \mathrm{~s}$. The frequency deviation is given by Fig. 23 and the control signal is given by Fig. 24. The peak value of the frequency deviation, settling time, ISE and the controller gain for Fig. 25 are given in Table 3.

To verify the robustness of the proposed FOPID controller, the system parameters were either increase by $50 \%$ or decrease by $50 \%$. The first case is a $50 \%$ increase in the values of $K_{p}$ and $T_{p}$, the new values are $K_{p}=180, T_{p}=30$. The frequency deviation is given by Fig. 24 . The second case is a $50 \%$ increase in the values of $K_{p}$ and $50 \%$ decrease in the values of $T_{p}$. The third case is a $50 \%$ increase in all system parameters. Due the limitation of space, the plots are not plotted here. To further verify the efficiency of the proposed controller, a random and ramp rate varying step change in load disturbance is applied to the system in Fig. 14. The frequency deviation for the random change in load disturbance and ramp rate varying change in load disturbance are given by Fig. 17 and Fig. 18 respectively.

\section{B. Simulations for adding time delay, GDB and GRC to one area network}

The system parameters of the one area power system with time delay, GDB and GRC in Fig. 15 are given as follows: $K_{p}=120, T_{p}=20, T_{t}=0.3, T_{g}=0.08, R=2.4$. The variable time delay was set from $0.1 \mathrm{~s}$ to a maximum delay of 10s. The Anti-GDB gain is $K_{c}=2$. The dead band of $0.0005 \mathrm{p} . \mathrm{u} / \mathrm{Hz}$ was used as the upper and lower bound of the dead zone in the Simulink model. The Anti-GRC gain is $K_{c}=$ 3 , The generation rate of 0.1 P.u. MW/min which is 0.0017 p.u. MW/sec was used as the upper and lower bound of the limiter in the Simulink model. A step change in load disturbance of $0.01 \mathrm{pu}$ was applied to Fig. 15, at time $\mathrm{t}=1 \mathrm{~s}$. The frequency deviation is given by Fig. 26. The peak value of the frequency deviation, settling time, ISE and the controller gains are presented in Table 4.

\section{Simulation for the two area power system without physical constraints.}

The system parameter for the power system in Fig. 14 was also applied to the power designed with time delay, GDB and GRC given in Fig. 16. For the two area power system given in Fig. 11, a step change in load disturbance of $0.01 \mathrm{pu}$ was applied to the system at time $\mathrm{t}=1 \mathrm{~s}$ before adding time delay, GRC and GDB. The frequency deviation for area one, area two, tie-line power deviation, ACE for area one and two are given in Fig. 27 to Fig. 31 respectively. The peak value of the frequency deviation, settling time, ISE and the controller gain of all the methods for area one, area two and tie-line power deviation are presented in Table 5.

\section{$D$. Simulation for the two area power system with time delay, GRC and GDB}

The system parameter for the power system in Fig. 1 was also applied to the power designed with time delay, GDB and GRC given in Fig. 17. The Anti-GDB gain was set $K_{c}=2$, the Anti-GRC gain was set as $K_{c}=3$, the dead band of $0.0005 \mathrm{p} . \mathrm{u} / \mathrm{Hz}$ was used as the upper and lower bound of the dead zone in the Simulink model. The generation rate of 0.1 P.u. which is 0.0017 p.u. MW/sec was used as the upper and lower bound of the limiter in the Simulink model. A step change in load disturbance of 0.01 pu was applied to Fig. 17 at time $\mathrm{t}=1 \mathrm{~s}$. The frequency deviation for area one, area two, tie-line power deviation, ACE for area one and two are given in Fig. 33 to Fig. 37 respectively. The peak value of the frequency deviation, settling time, ISE and the controller gain of all the methods for area one, area two and tie-line power deviation are presented in Table 6. 


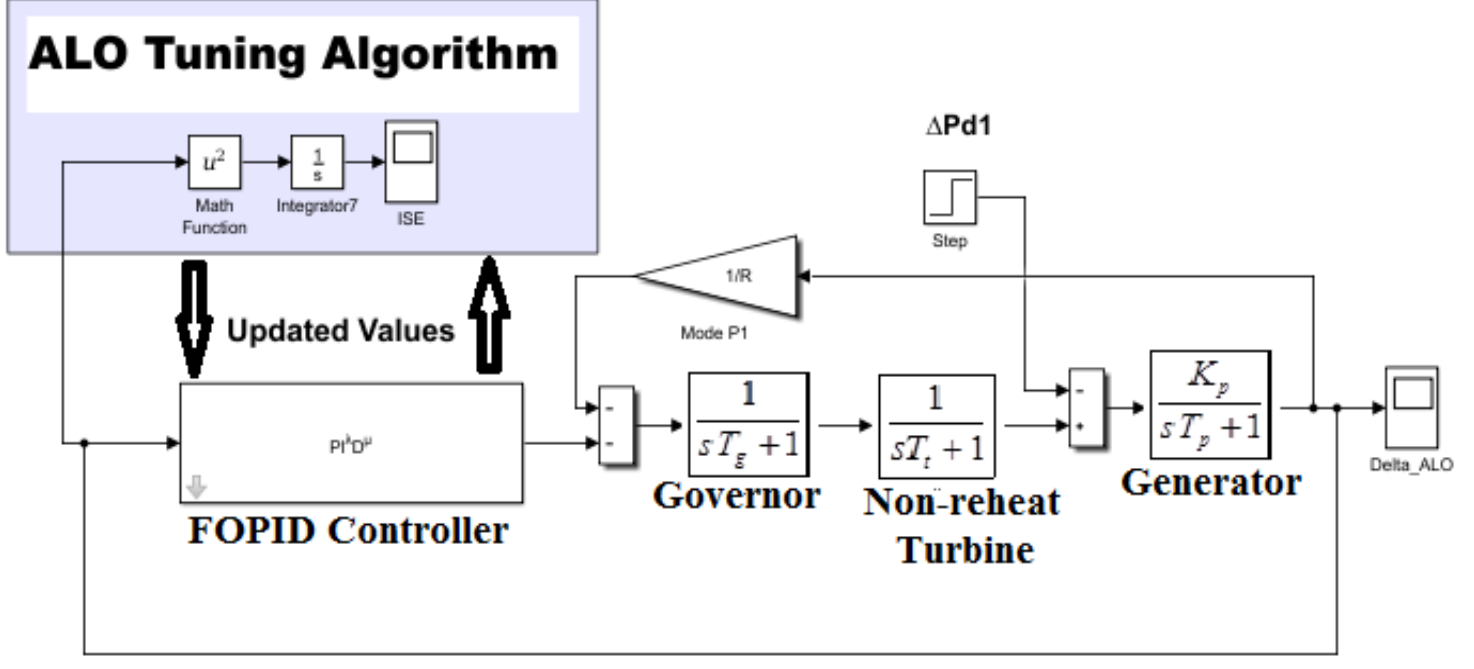

Fig. 13. ALO Algorithm Link to the Power System

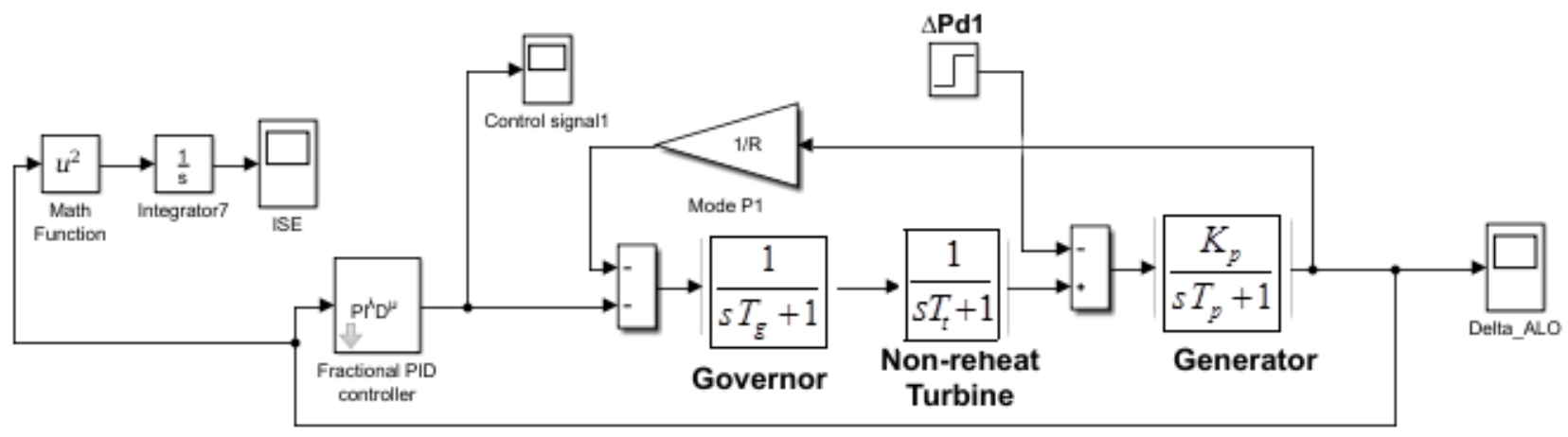

Fig. 14. Single Area Thermal Power System without physical constraints

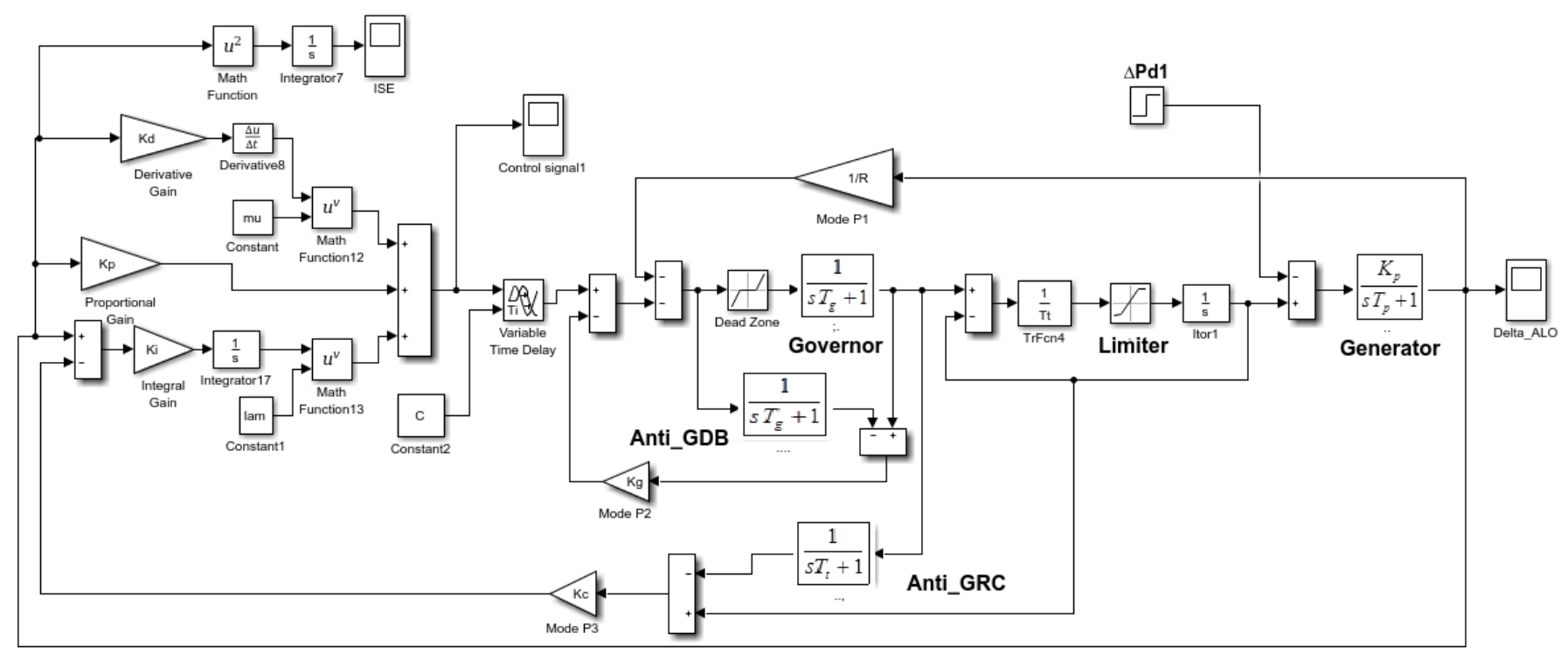

Fig. 15. Single Area Thermal Power System with GDB, GRC and Time Delay 


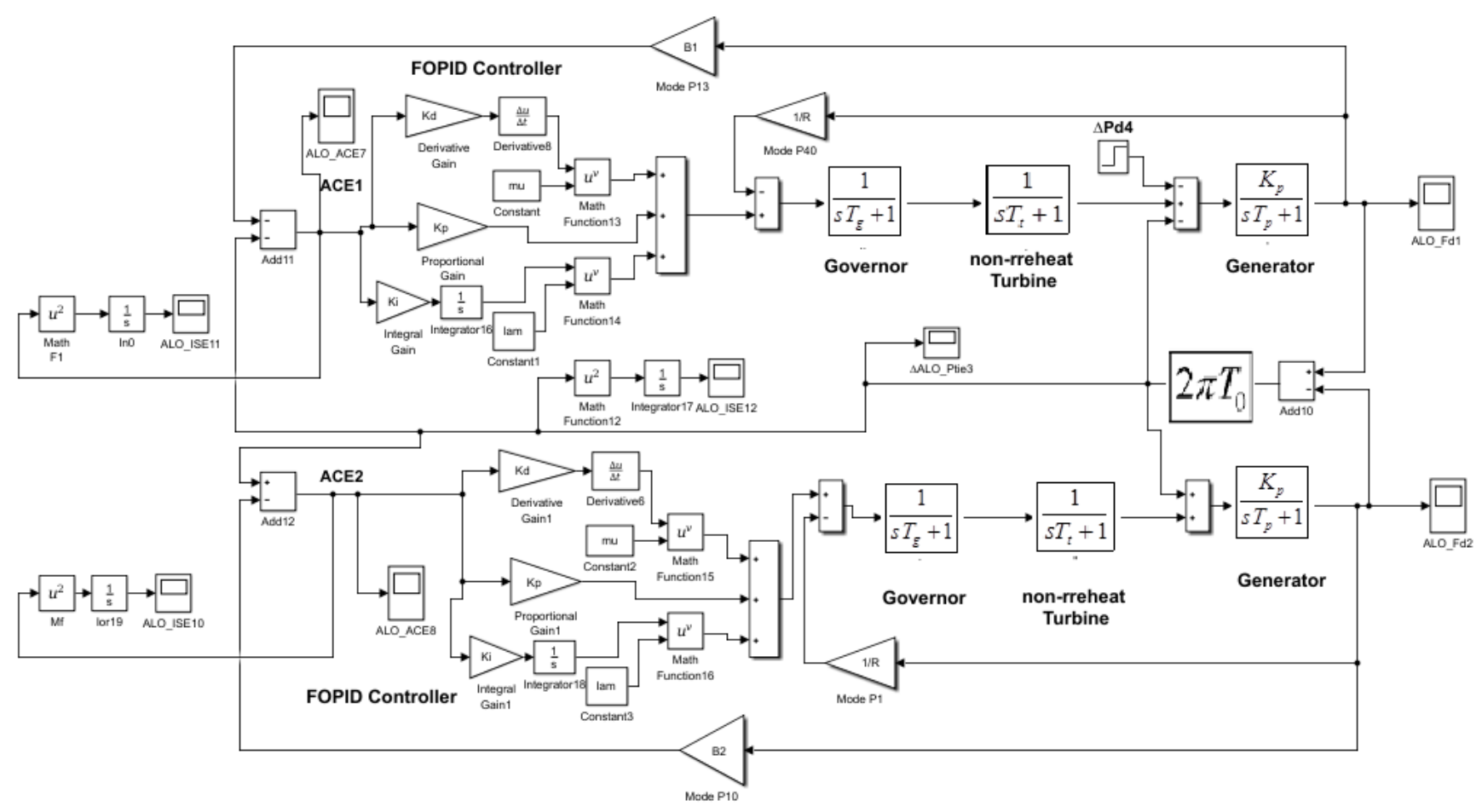

Fig. 16. Two Area Thermal Power System.

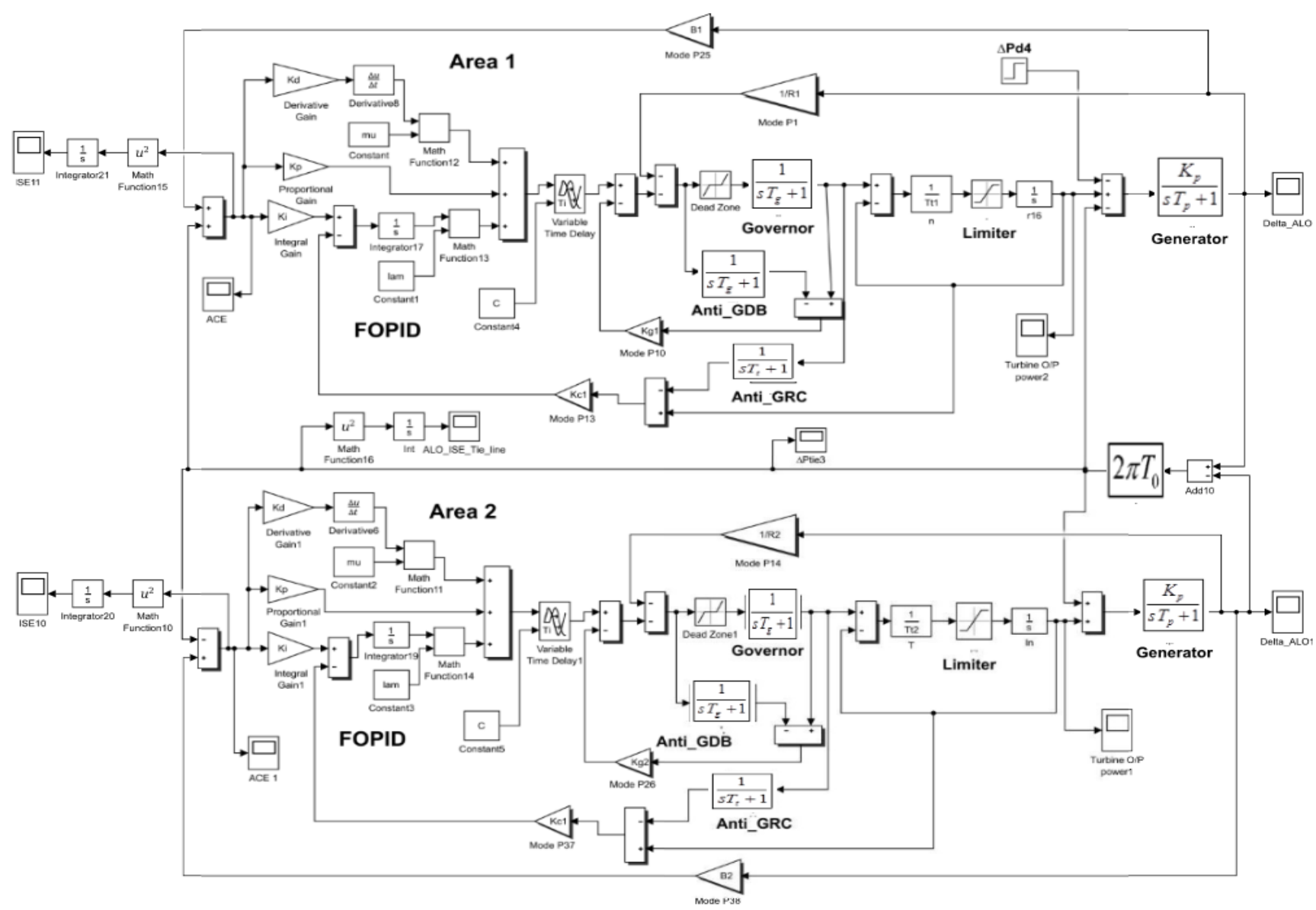

Fig. 17. Two Area Thermal Power System with GDB, GRC and Time Delay. 


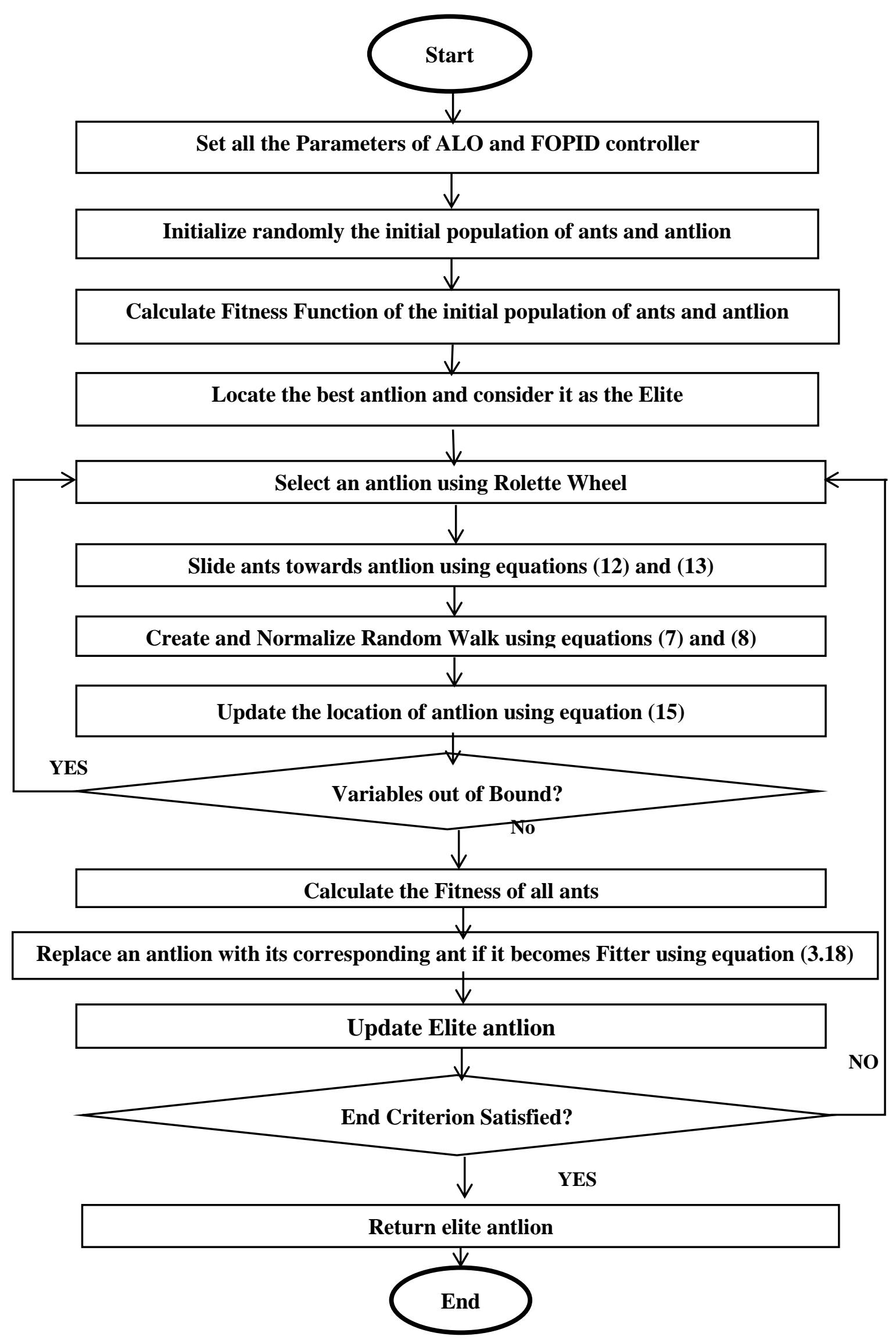

Fig. 18. Flowchart for the Implementation of ALO algorithm 
The flowchart for optimizing the gain of the FOPID controller is given in Fig 18. An optimal value is obtained whenever an ant is consumed by the antlion. From the figure, the antlion parameters and FOPID controller were first initialized. These parameters includes: the number of search agents, upper and lower bound, the number of iterations, number of dimension and the parameter of the FOPID controller. The antlion and ant position were then initialize using the number of search agents, the dimension, the lower and upper bound. The fitness function of the ants and antlion was then calculated using their initial position and the objective function.to the ant is then located. Since there is

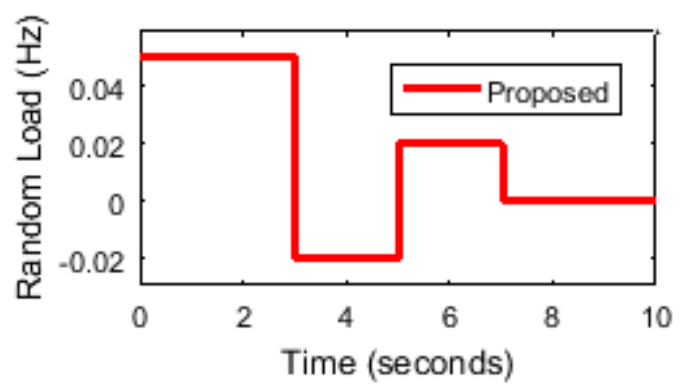

Fig 19. Random Load Input Signal

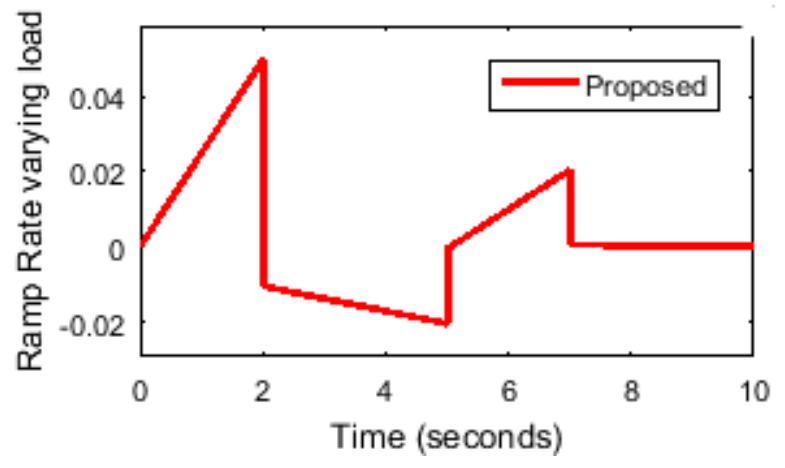

Fig. 20. Ramp Rate Varying Load

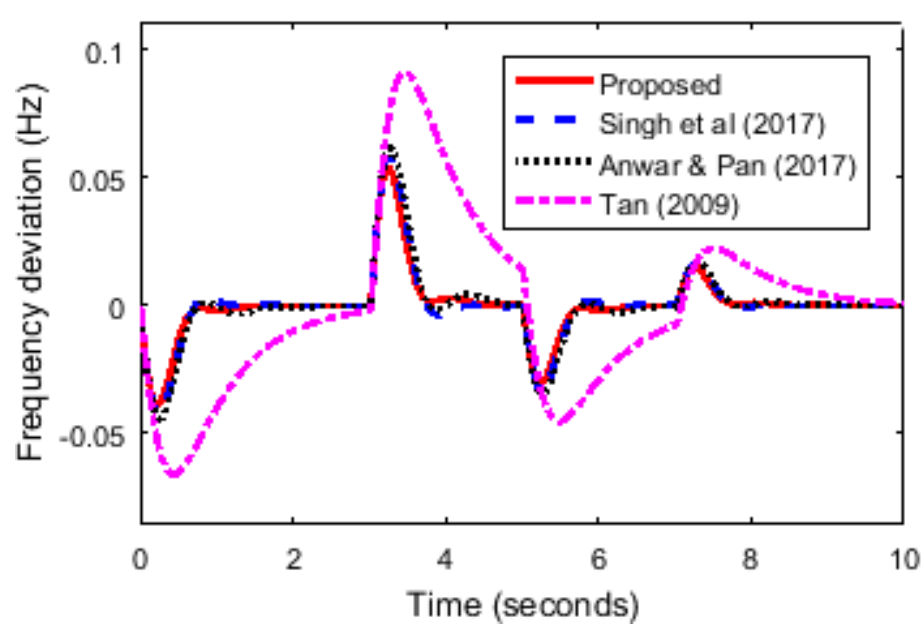

Fig. 21. Frequency Deviation for Random Load of power system without constraints more than one antlion in the trap, the closest antlion the ant is then located. The antlion is then selected using the Rolette Wheel operation. The antlion then throws sand towards the middle of the trap to slide the ant toward the antlion and then update its location. If the variable (ant) is out of bound, another antlion is then selected, else, the fitness of the ants is then calculated using their initial position and the objective function. If the ant becomes fitter, it is then replaced by the antlion. The antlion is expected to guide the ant towards the promising region of the search space by moving randomly using Rolette wheel and elite.

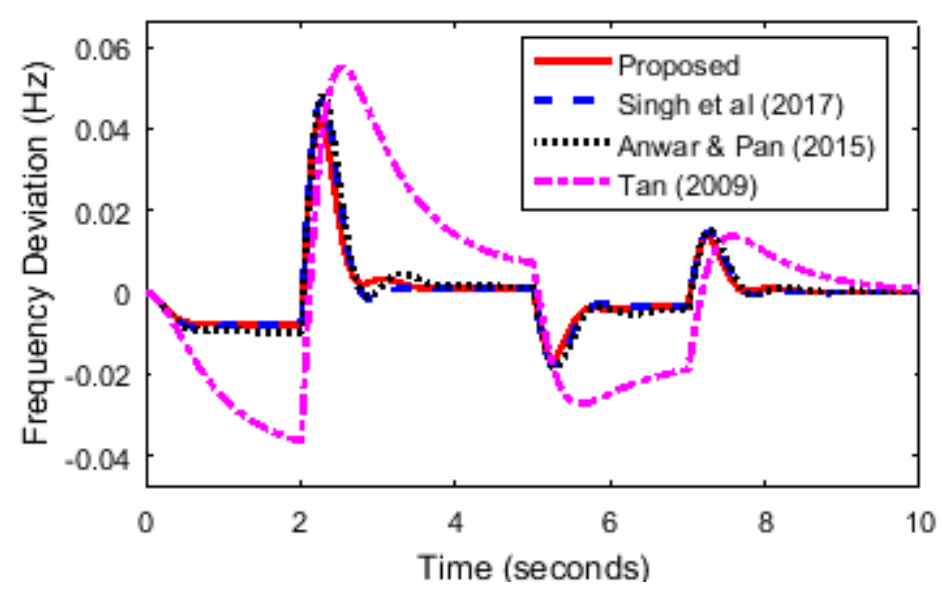

Fig. 22. Frequency Deviation for Ramp Rate Varying Load of power system without constraints

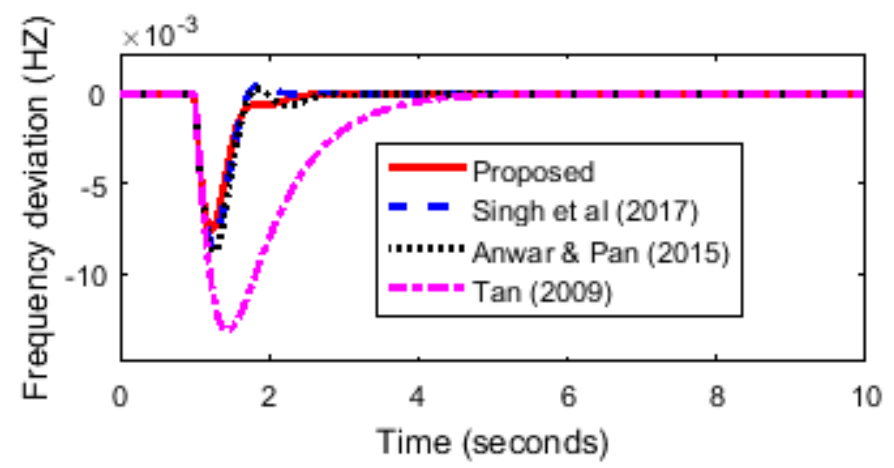

Fig. 23. Frequency Deviation for Nominal Parameters for one area power system

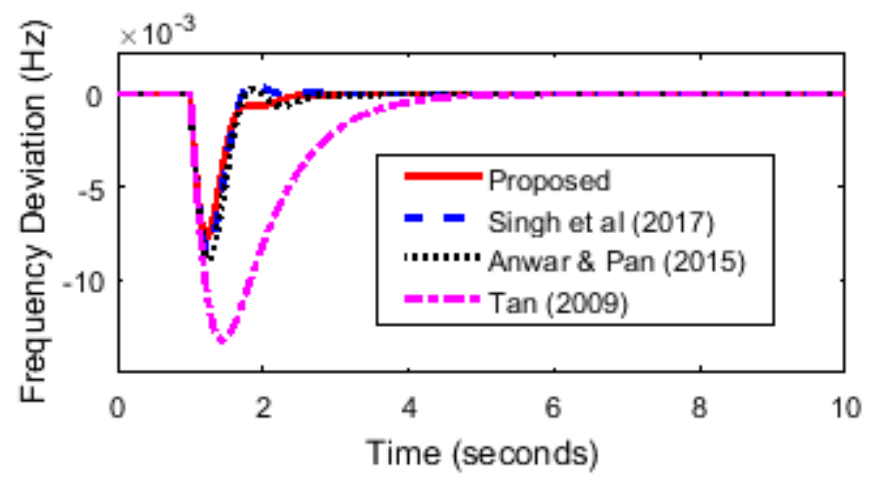

Fig. 24. Frequency Deviation for $50 \%$ increase in $K_{p}$ and $T_{p}$ for one area power system 


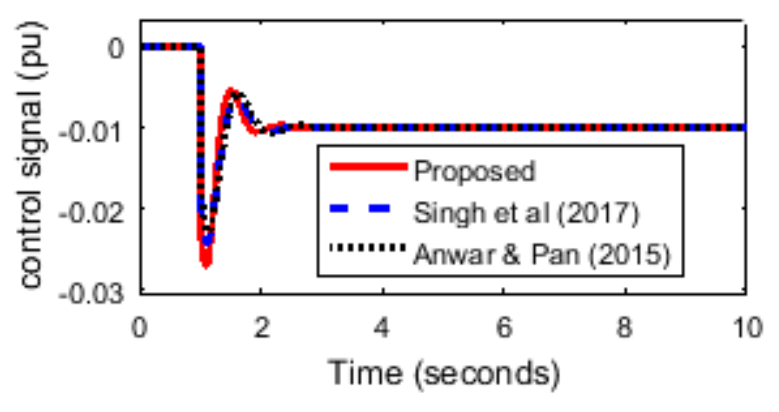

Fig. 25. Control Signal for one area power system

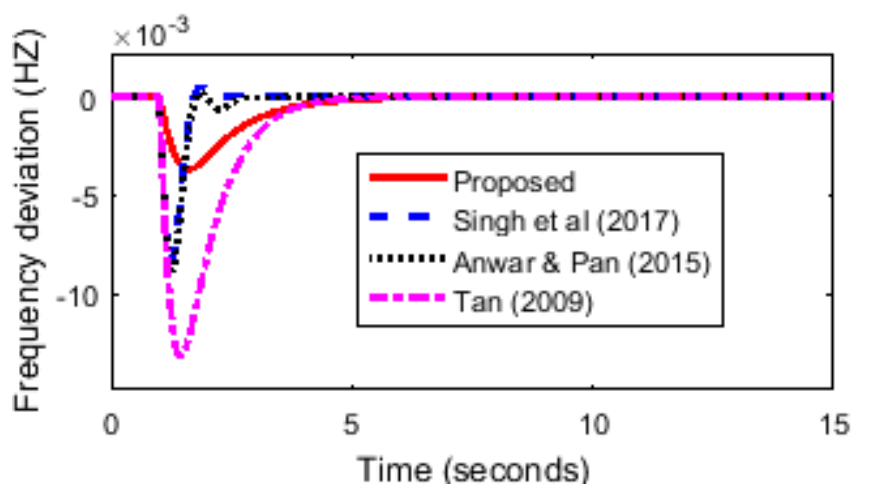

Fig. 26. Frequency deviation for one area power system with time delay, GRC and GDB

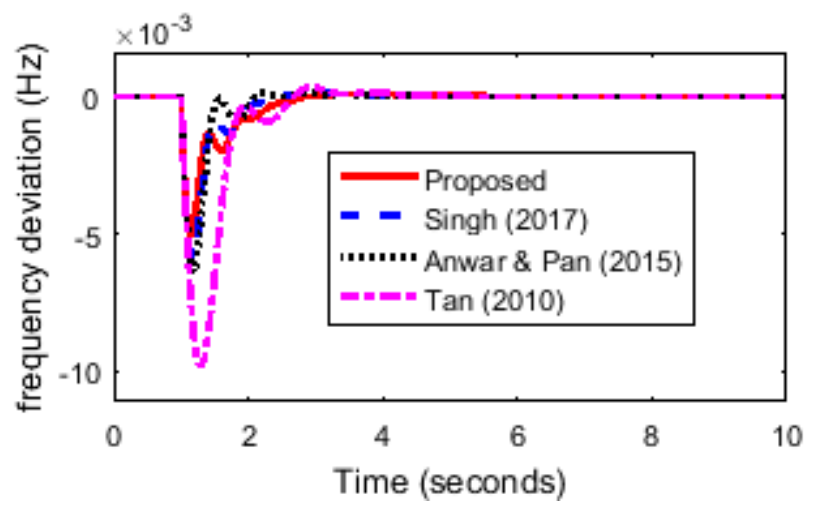

Fig. 27. Frequency deviation for area one power system without physical constraints

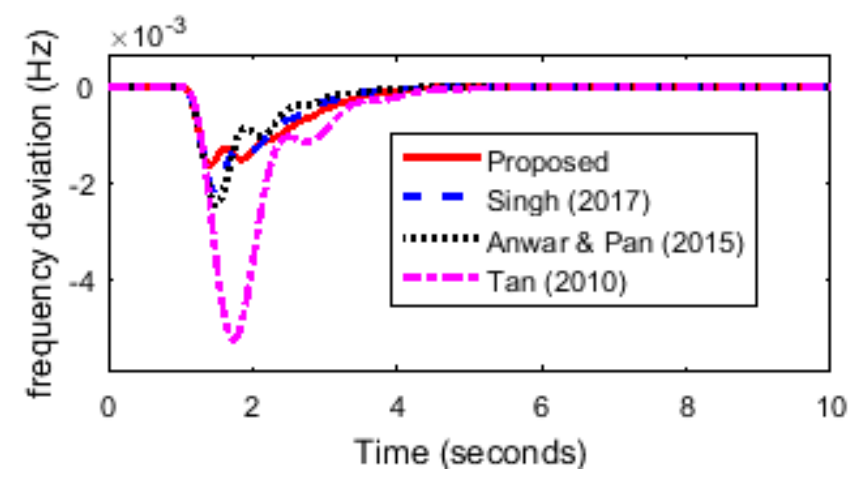

Fig. 28. Frequency deviation for area two power system without physical constraints

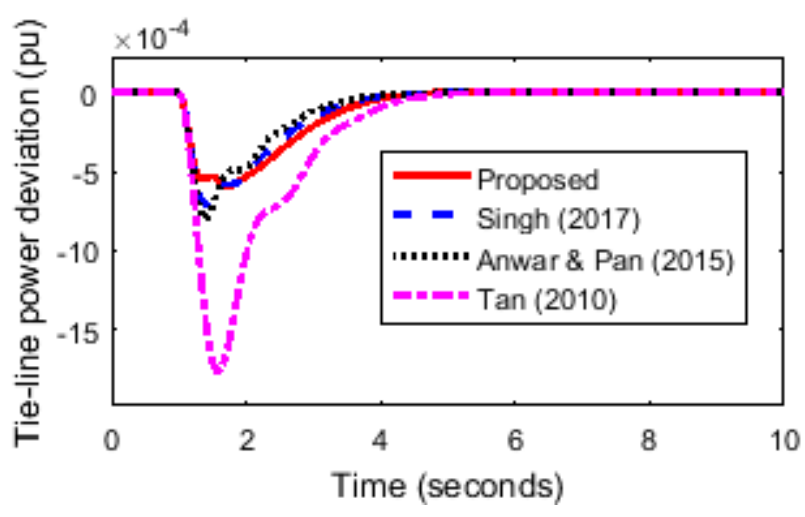

Fig. 29. Tie-line power deviation of the two areas

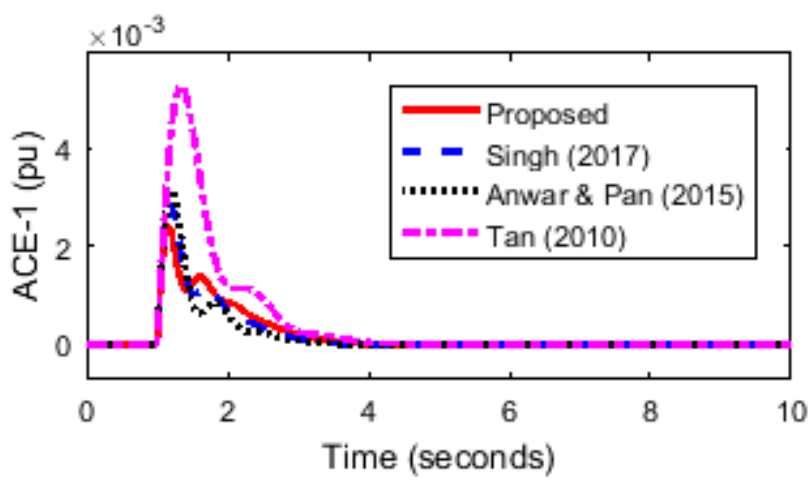

Fig. 30. Area control error for area one of the two area power system without physical constraints

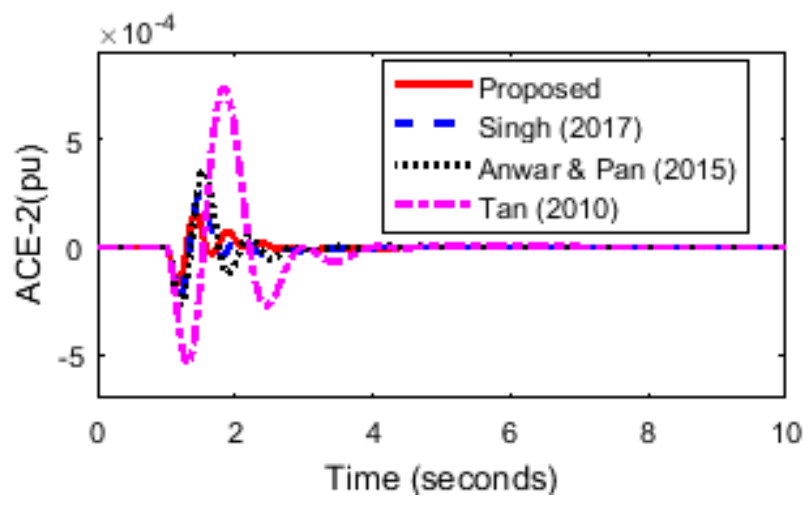

Fig. 32. Area control error for area two of the two area power system without physical constraints

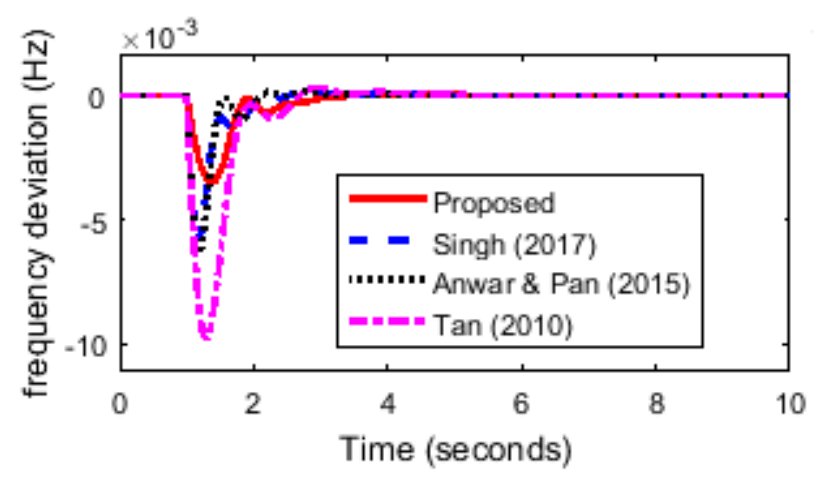

Fig. 33. Frequency deviation of area one for the two area power system with time delay. GRC and GDB. 


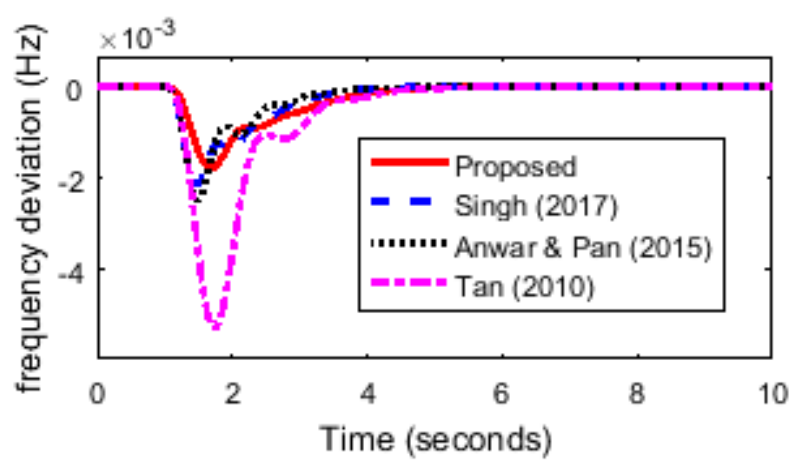

Fig. 34. Frequency deviation of area two for the two area power system with time delay. GRC and GDB.

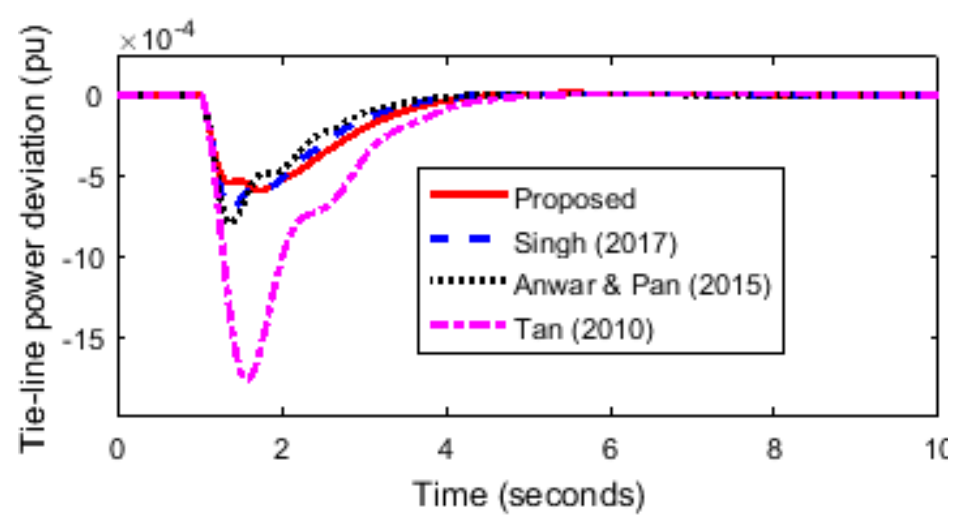

Fig. 35. Tie-line power deviation of the two area power system with time delay. GRC and GDB

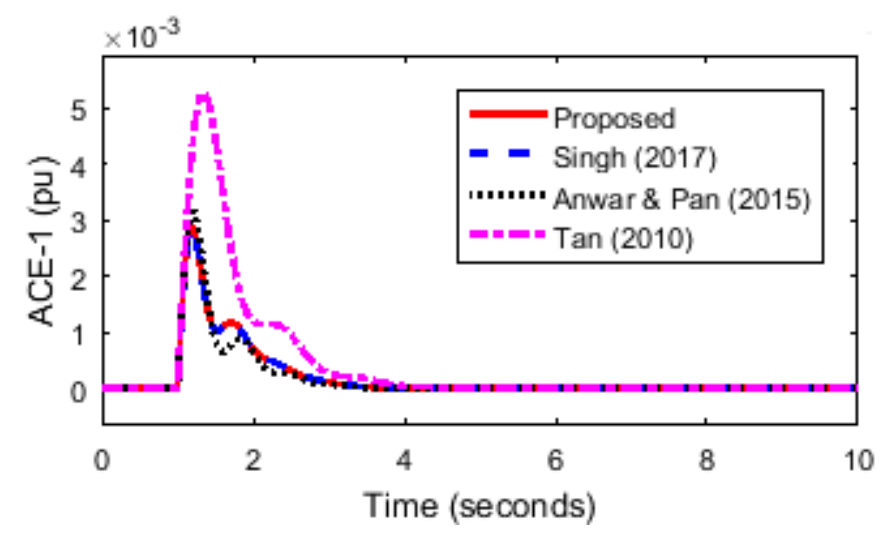

Fig. 36. ACE-1 of area one for the two area power system with time delay, GDB and GRC

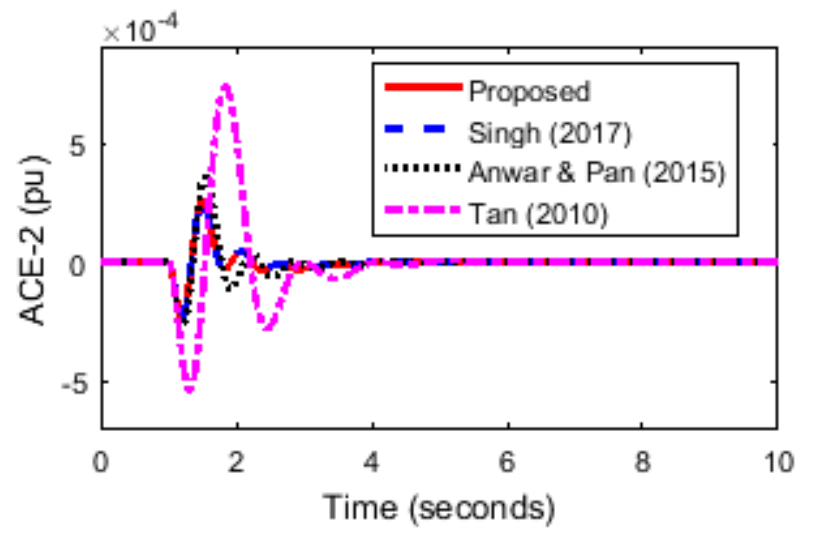

Fig. 37. ACE-2 of area two for the two area power system with time delay, GDB and GRC.

TABLE 3. COMPARATIVE ANALYSIS FOR ONE AREA POWER SYSTEM WITHOUT CONSTRAINTS GIVEN IN FIG. 23 AND FIG. 24

\begin{tabular}{|c|c|c|c|c|c|c|c|c|c|c|c|}
\hline \multirow[t]{2}{*}{ Method } & \multirow[b]{2}{*}{$\mathrm{Kp}$} & \multicolumn{4}{|c|}{ Controller gains } & \multirow{2}{*}{$\begin{array}{c}\text { Nominal plant } \\
\text { Frequency } \\
\text { Deviation }\left(\times 10^{-3}\right) \\
\mathrm{Hz} \\
\end{array}$} & \multicolumn{2}{|l|}{ Parameter } & \multicolumn{3}{|c|}{$50 \%$ increase in $\mathrm{Kp}$ and $\mathrm{Tp}$} \\
\hline & & $\mathrm{Ki}$ & $\mathrm{Kd}$ & $\lambda$ & $\mu$ & & $\begin{array}{l}\text { Settling } \\
\text { time }(s)\end{array}$ & $\begin{array}{c}\text { ISE } \\
(\times \\
\left.10^{-5}\right) \\
\end{array}$ & $\begin{array}{l}\text { Frequency deviation } \\
\qquad\left(\times 10^{-3}\right) \mathrm{Hz}\end{array}$ & $\begin{array}{l}\text { Settling } \\
\text { time }(s)\end{array}$ & $\begin{array}{c}\text { ISE } \\
(\times \\
\left.10^{-5}\right) \\
\end{array}$ \\
\hline Proposed & 1.743 & 3.5 & 0.3655 & 1 & 1.014 & 6.8 & 2.01 & 1.707 & 6.8 & 2.01 & 1.707 \\
\hline Singh [1] & 1.5 & 3.15 & 0.31 & - & - & 7.5 & 2.274 & 2.11 & 7.5 & 2.274 & 2.11 \\
\hline Anwar [4] & 1.52 & 2.50 & 0.27 & - & - & 8.9 & 2.68 & 2.471 & 8.9 & 2.68 & 2.471 \\
\hline Tan [42] & 0.40 & 0.63 & 0.183 & - & - & 13.2 & 4.35 & 13.6 & 13.2 & 4.35 & 13.6 \\
\hline
\end{tabular}

TABle 4. COMPARATIVE ANALYSIS FOR ONE AREA THERMAL POWER SySTEM WITH GDB, GRC AND TIME DELAY GIVEN IN FIG. 26

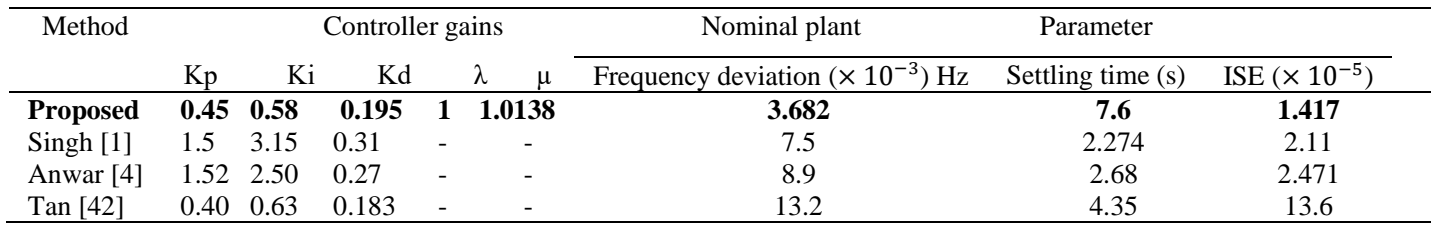

TABle 5. COMPARATIVE ANALYSIS FOR THE TWO AREA THERMAL POWER SySTEM WITHOUT CONSTRAINTS GIVEN IN FIG. 27, FIG. 28 AND FIG. 29

\begin{tabular}{|c|c|c|c|c|c|c|c|c|c|c|c|c|c|c|}
\hline \multirow[t]{2}{*}{ Method } & \multirow[b]{2}{*}{$\mathrm{Kp}$} & \multicolumn{4}{|c|}{ Controller gains } & \multicolumn{3}{|l|}{ Area one } & \multicolumn{3}{|l|}{ Area two } & \multicolumn{3}{|l|}{ Tie-line } \\
\hline & & $\mathrm{Ki}$ & $\mathrm{Kd}$ & & $\lambda$ & $\begin{array}{c}\text { Frequency } \\
\text { deviation } \\
\left(\times 10^{-3}\right) \\
\mathrm{Hz}\end{array}$ & $\begin{array}{l}\text { Settling } \\
\text { time (s) }\end{array}$ & $\begin{array}{c}\text { ISE } \\
(\times \\
\left.10^{-5}\right)\end{array}$ & $\begin{array}{c}\text { Frequency } \\
\text { deviation } \\
\left(\times 10^{-3}\right) \\
\mathrm{Hz}\end{array}$ & $\begin{array}{l}\text { Settling } \\
\text { time (s) }\end{array}$ & $\begin{array}{c}\text { ISE } \\
(\times \\
\left.10^{-5}\right)\end{array}$ & $\begin{array}{c}\text { Frequency } \\
\text { deviation } \\
\left(\times 10^{-3}\right) \\
\mathrm{Hz}\end{array}$ & $\begin{array}{l}\text { Settling } \\
\text { time (s) }\end{array}$ & $\begin{array}{c}\text { ISE } \\
(\times \\
\left.10^{-5}\right)\end{array}$ \\
\hline Proposed & 4.45 & 5.24 & 1.75 & 1 & 0.992 & 5.075 & 2.125 & 0.2375 & 1.636 & 2.032 & 0.1886 & 5.948 & 2.831 & 0.3118 \\
\hline Singh [1] & 4.25 & 5.5 & 1.35 & - & - & 5.849 & 2.769 & 0.7848 & 2.13 & 2.274 & 0.2625 & 7.1 & 3.26 & 0.4198 \\
\hline $\begin{array}{l}\text { Anwar } \\
\text { [4] }\end{array}$ & 3.55 & 5.95 & 1.22 & - & - & 6.4 & 3.51 & 0.9325 & 2.5 & 3.16 & 0.2939 & 8.49 & 3.37 & 0.453 \\
\hline Tan [42] & 1.56 & 2.39 & 0.525 & - & - & 9.9 & 3.31 & 3.521 & 5.3 & 4.4 & 1.53 & 17.61 & 4.43 & 2.19 \\
\hline
\end{tabular}


TABLE 6. COMPARATIVE ANALYSIS FOR THE TWO AREA THERMAL POWER SYSTEM WITH GDB, GRC AND TIME DELAY IN FIG. 33 , FIG 34 AND FIG. 35

\begin{tabular}{|c|c|c|c|c|c|c|c|c|c|c|c|c|c|c|}
\hline \multirow[t]{2}{*}{ Method } & \multirow[b]{2}{*}{$\mathrm{Kp}$} & \multirow[b]{2}{*}{$\mathrm{Ki}$} & \multicolumn{3}{|c|}{ Controller gains } & \multicolumn{3}{|l|}{ Area one } & \multicolumn{3}{|l|}{ Area two } & \multicolumn{3}{|l|}{ Tie-line } \\
\hline & & & $\mathrm{Kd}$ & $\lambda$ & $\mu$ & $\begin{array}{c}\text { Frequency } \\
\text { deviation } \\
\left(\times 10^{-3}\right) \\
\mathrm{Hz}\end{array}$ & $\begin{array}{l}\text { Settling } \\
\text { time (s) }\end{array}$ & $\begin{array}{c}\text { ISE } \\
(\times \\
\left.10^{-5}\right)\end{array}$ & $\begin{array}{c}\text { Frequency } \\
\text { deviation } \\
\left(\times 10^{-3}\right) \\
\mathrm{Hz}\end{array}$ & $\begin{array}{l}\text { Settling } \\
\text { time (s) }\end{array}$ & $\begin{array}{c}\text { ISE } \\
(\times \\
\left.10^{-5}\right)\end{array}$ & $\begin{array}{c}\text { Frequency } \\
\text { deviation } \\
\left(\times 10^{-3}\right) \\
\mathrm{Hz}\end{array}$ & $\begin{array}{l}\text { Settling } \\
\text { time }(s)\end{array}$ & $\begin{array}{c}\text { ISE } \\
(\times \\
\left.10^{-5}\right)\end{array}$ \\
\hline Proposed & 4.45 & 5.24 & 1.75 & 1 & 0.992 & 3.493 & 3.71 & 0.2055 & 1.733 & 5.19 & 0.0968 & 6.966 & 5.36 & 0.3865 \\
\hline Singh [1] & 4.25 & 5.5 & 1.35 & - & - & 5.849 & 2.769 & 0.7848 & 2.13 & 2.274 & 0.2625 & 7.1 & 3.26 & 0.4198 \\
\hline $\begin{array}{l}\text { Anwar } \\
\text { [4] }\end{array}$ & 3.55 & 5.95 & 1.22 & - & - & 6.4 & 3.51 & 0.9325 & 2.5 & 3.16 & 0.2939 & 8.49 & 3.37 & 0.453 \\
\hline Tan [42] & 1.56 & 2.39 & 0.525 & - & - & 9.9 & 3.31 & 3.521 & 5.3 & 4.4 & 1.53 & 17.61 & 4.43 & 2.19 \\
\hline
\end{tabular}

\section{E. Discussion of results}

From the Tables above, all the results showed that the proposed FOPID controller was able to minimize frequency deviation better than the controllers designed by Singh et al. [1], Anwar and Pan [4] as well as Tan [42]. The proposed FOPID controller was able to minimize the error between the generated power and load demand by, $7 \%$ better than the controller designed by Singh et al. [1]. The controller designed by Singh et al. [1] is the closest in performance to the proposed FOPID controller. The FOPID controller was able to reduce the settling time of the system to $2.01 \mathrm{~s}$ from $2.274 \mathrm{~s}$ obtained by Singh et al. [1]. This indicates that the proposed FOPID controller was able to balance the generated power and load demand faster than other designed methods given in Table 3. As seen from Table 3, when the values of $\mathrm{Kp}$ and $\mathrm{Tp}$ were increased by $50 \%$, the performance of the proposed FOPID controller continues to meet the designed specifications. That is to minimize the error between the generated power and load demand, better than other designed method given in the Table 3 .

The comparative analysis of the one area power system with generation rate constraints, governor dead band and time delay is given Table 4 . The proposed method was able to minimize frequency deviation better, despite the constraints that were added to the power system. When compared to the results obtained by Singh et al. [1], Anwar and Pan [4] as well as Tan [42] for the power system without any constraints. The settling time of the system for the proposed method and the controllers designed by Singh et al. [1], Anwar and Pan [4] as well as Tan [42] are 7.6s, 2.27s, $2.68 \mathrm{~s}$ and $4.35 \mathrm{~s}$ respectively. This shows that the proposed FOPID controller took a longer time to balance the generated power and load demand when compared to other designed methods given in Table 4. This was because the proposed power system were designed with physical constraints and the results was compared to the power system without physical constraints given in Table 4.

From Table 5, it is observed that the proposed method was able to minimize frequency deviation better than the controllers designed by Singh et al.[1], Anwar and Pan [4] as well as Tan[42]. For area one, the frequency deviation was minimized to $0.00507 \mathrm{~Hz}$ from $0.00584 \mathrm{~Hz}$ obtained by Singh et al. [1]. The ISE was reduced to $0.237 \times 10^{-5}$ from $0.7848 \times 10^{-5}$ obtained by Singh et al. [1]. This shows that the proposed FOPID controller was able to minimize the error between the generated power and load demand, 8\% better than the controller designed by Singh et al. [1] and other designed methods given in Table 5. The settling time of the system was reduced to $2.12 \mathrm{~s}$ from $2.76 \mathrm{~s}$ obtained by
Singh et al. [1]. This indicates that the proposed FOPID controller was able to balance the generated power and load demand faster than other designed methods given in Table 5. For area two, the frequency deviation was minimized to $0.00163 \mathrm{~Hz}$ from $0.00213 \mathrm{~Hz}$ obtained by Singh et al. [1]. The ISE was reduced to $0.1886 \times 10^{-6}$ from $0.2625 \times 10^{-6}$ obtained by Singh et al. [1]. This shows that the proposed FOPID controller was able to minimize the error between the generated power and load demand, $5 \%$ better than the controller designed by Singh et al. [1]. The settling time of the system was reduced to $2.03 \mathrm{~s}$ from $2.27 \mathrm{~s}$ obtained by Singh et al. [1]. This shows that the proposed FOPID controller was able to minimize the error between the generated power and load demand better and faster than the controller designed by Singh et al. [1], Anwar \& Pan [4] and Tan [42]. For the tie-line, the power deviation was minimized to $0.00594 \mathrm{pu}$ from $0.0071 \mathrm{pu}$ obtained by Singh et al. [1]. The ISE was reduced to $0.3118 \times 10^{-6}$ from $0.4198 \times 10^{-6}$ obtained by Singh et al. [1]. This shows that the proposed FOPID controller was able to minimize the error between the scheduled and actual power, $10 \%$ better than the controller designed by Singh et al. [1]. The settling time of the system was reduced to 2.83 s from 3.26 s obtained by Singh et al. [1]. This indicates that the proposed FOPID controller was able to balance the scheduled and actual power faster than the controllers designed by Singh et al. [1], Anwar \& Pan [4] and Tan [42]. For the area control error of area one given in Fig. 30, the power deviation of the proposed methods and that of Singh et al. [1], Anwar \& Pan [4] and Tan [42] area 0.0022pu, $0.0025 \mathrm{pu}, 0.0028 \mathrm{pu}$ and $0.0052 \mathrm{pu}$ respectively. For the area control error of area two given in Fig. 31, the power deviation of the proposed method and that of Singh et al. [1], Anwar \& Pan [4] and Tan [42] are 0.00012pu, 0.00019pu, 0.00025pu and $0.00074 \mathrm{pu}$ respectively. This shows that the proposed method was able to reduce the error between the scheduled and actual power in area one and two, better than the designed methods by Singh et al. [1], Anwar \& Pan [4] and Tan [42].

The comparative analysis between the proposed methods for the power system designed with GRC, GDB, time delay and other designed methods for the power system without constraints are given in Table 6. The frequency deviation was minimized to $0.00349 \mathrm{~Hz}$ from $0.00584 \mathrm{~Hz}$ obtained by Singh et al. [1]. The ISE for the proposed method was minimized to $0.2055 \times 10^{-5}$ from $0.7848 \times 10^{-5}$ obtained by Singh et al. [1]. For area two, the frequency deviation for the proposed method and the controller designed by Singh et al., [1] are $0.00173 \mathrm{~Hz}$ and $0.00213 \mathrm{~Hz}$ respectively. The ISE of the proposed method and the controller designed by Singh et al. [1] are $0.0968 \times 10^{-5}$ and $0.2625 \times 10^{-5}$ respectively. The tie-line power deviation for the proposed method and the controller designed by Singh et al. [1] $0.006966 \mathrm{pu}$ and $0.0071 \mathrm{pu}$ respectively. The ISE of the proposed method and the controller designed by Singh et al. [1] are 
$0.3865 \times 10^{-5}$ and $0.4198 \times 10^{-5}$ respectively. This shows that the proposed method was able to minimize the error between the generated power and load demand for area one, area two and tie-line, $37 \%, 6 \%$ and $7 \%$ respectively better, than other designed methods given in Table 6 . The settling time of the system for the proposed method and the controller designed by Singh et al. [1] for area one, area two and tie-line are $3.71 \mathrm{~s}$ and $2.76 \mathrm{~s}, 5.19 \mathrm{~s}$ and $2.27 \mathrm{~s}, 5.36 \mathrm{~s}$ and $3.26 \mathrm{~s}$ respectively. This shows that the proposed method took a longer time to balance the generated power and load demand when compared to other designed methods given in Table 6. This was as a result of the time delay, GDB and GRC that was added to the power system of the proposed method. For the area control error of area one given in Fig. 36, the power deviation of the proposed methods and that of Singh et al. [1], Anwar \& Pan [4] and Tan [42] area 0.0027pu, 0.0025pu, $0.0028 \mathrm{pu}$ and $0.0052 \mathrm{pu}$ respectively. For the area control error of area two given in Fig. 37, the power deviation of the proposed method and that of Singh et al. [1], Anwar \& Pan [4] and Tan [42] are 0.00022pu, 0.00019pu, 0.00025pu and $0.00074 \mathrm{pu}$ respectively. This shows that the controller designed by Singh et al. [1] was able to reduce the error between the scheduled and actual power in area one and two, better than the proposed FOPID controller, Anwar \& Pan [4] and Tan [42]. This was as a result of the physical constraints that were added to the proposed power system designed.

\section{CONCLUSION AND FURTHER WOKS}

In this paper, the development of a Fractional Order PID (FOPID) controller to minimize the effects of governor dead band, generation rate constraints and communication time delay in a single and two areas has been presented. The power system designed by Singh et al. [1] for a one and two area network was first adopted. Different cases of parameter uncertainties, random load disturbance and ramp rate varying load disturbance were considered for a single area and two area thermal power systems. The gains of the proposed FOPID controller were optimized using the antlion algorithm. The integer part of the FOPID controller was first optimized followed by the fractional part of the controller. Physical constraints such as generation rate constraints, Governor dead band and time delay were added to the one and two area power system designed by Singh et al. [1]. To minimize the effects of the governor dead band, generation rate constraints and time delay, and the anti-windup scheme was added to the designed power systems. The Antlion optimization algorithm was linked to each of the designed power system. The objective function for minimization was Integral Square Error (ISE) while the errors that were minimized are frequency deviation, tie-line power deviation and area control error. Simulations were carried out on each of the various cases considered and optimal values of the FOPID controller were obtained.

Results obtained shows that the proposed FOPID controller outperformed the controllers designed Singh et al. [1], Anwar \& Pan [4] and Tan [42] in terms of frequency deviation, tie-line power deviation and area control error. This is for when the power system was with and without time delay, GRC and GDB. However, when Time delay, GRC and GDB were added to one and two area power system incrementally, and the results obtained where compared with the power system designed by Singh et al. [1], without any constraints. It was observed that the proposed FOPID controller took a longer time to balance the generated power and load demand. These physical constraints (time delay, GDB and GRC) exist in any practical power system, as such, to study the behavior of a real power systems, it is requiring to include these constraints in the power system design. As such, boiler dynamics, which is a device that produces steam under pressure due to sudden change in load demand, can be included to the constraints for further research. Again, as the demand for power increases, it is essential to increase the number of interconnected areas such that the generating devices are not overloaded. This is required to improve the quality reliability of the power system. Extending the combination of the physical constraints given above into a three or four area power system becomes paramount in studying a real interconnected power system.

\section{REFERENCES}

[1] V. P. Singh, N. Kishor and P. Samuel, "Improved Load Frequency Control of Power System using LMI based PID approach," Journal of the Franklin Institute, vol. 354, pp. 6805-6830, August 2017. https://dx.doi.org/10.1016/j.jfranklin.2017.08.031

[2] M. I. Alomoush, "Load Frequency Control and Automatic Generation Control Using Fractional-order Controllers," Electrical Engineering, vol. 1, pp. 357-368, Springer, January 2010.

[3] N. A. S. Anitha and G. R. Rao, "Fractional Order PID Controller Design for Two Area Load Frequency Control Using Genetic Algorithm," International Journal of Emerging Trends in Electrical and Electronics, vol. 10, Issue. 10, pp. 75-79, October 2014.

[4] Md. N. Anwar and S. Pan, "A new PID Load Frequency Controller Design method in Frequency Domain through Direct Synthesis approach," International Journal of Electrical Power and Energy Systems, vol. 67, pp. 560-569, January, 2015. https://dx.doi.org/10.1016/j.ijepes.2014.12.024

[5] S. S. Aung and Z. M. Htike, "Modeling and Simulation of Load Frequency Control for Three Area Power System Using Proportional Integral Derivative (PID) Controller," American Scientific Research Journal for Engineering, Technology, and Sciences (ASRJETS), vol. 26, no 2, pp. 301-315, August 2016.

[6] K. Arora, P. Kaur and V. K. Kamboj, "Problems and Solutions of Various Areas of Load Frequency Control of Power System," International Journal on Future Revolution in Computer Science \& Communication Engineering, vol. 4, no. 3, pp. 280-285, April 2018.

[7] P. Balasundaram and C. I. Akilandam, "ABC Algorithm based LoadFrequency Controller for an interconnected Power System Considering nonlinearities and Coordinated with UPFC and RFB," International Journal of Engineering and Innovative Technology (IJEIT), vol. 1, Issue 3, pp. 234-255, March 2012.

[8] S. P. Behera and A. Biswal, "Design and Analysis of TIDF controller in AGC with Thyristor Controlled series capacitor," International Journal of Innovative Research in Electrical, Electronics, Instrumentation and Control Engineering, vol. 5, Issue 3, pp. 223.231, March 2017. https://dx.doi.org/10.17148/ijireeice.2017.5319.

[9] Y. K. Bhateshvar, "Intelligent Control and Optimization for Power Frequency Balance in Multi-Generation System," Ph.D. Thesis, Birla Institute of Technology and Science India.

[10] J. Y. Cao and B. G. Cao, "Design of Fractional Order Controller Based on Particle Swarm Optimization," International Journal of Control, Automation and Systems, vol. 4, no. 6, pp. 775-781, December 2006.

[11] V. Celik, M. T. Ozdemir and G. Bayrak, "The effects on stability region of the fractional-order PI controller for one-area time-delayed loadfrequency control systems," Transactions of the Institute of Measurement and Control, vol. 1, pp. 1-13, December 2016. https://dx.doi.org/10.1177/0142331216642839

[12] M. Chiranjeevi and V. S. G. Lakshmi, "Design of PSO based Fractional order Load Frequency controller for two area power system," Journal of Electrical and Electronics Engineering (IOSR-JEEE), vol. 9, no. 6, pp. 67-74, December 2014

[13] A. Delassi, S. Arif and L. Mokrani, "Load frequency control problem in interconnected power systems using robust fractional $\mathrm{PI}^{\lambda} \mathrm{D}$ controller," Ain Shams Engineering Journal, vol. 1, pp. 1-12, October 2015. https://dx.doi.org/10.1016/j.asej.2015.10.004.

[14] Y. Deng and W. Liu, "Model Predictive Load Frequency Control of Two Area Interconnected Time Delay Power System with TCSC," 2nd 
Asia Conference on Power and Electrical Engineering (ACPEE), vol. 199, pp. 1-7, August 2017. https://dx.doi.org/10.1088/1757899X/199/1/012064

[15] E. E. Ejegi, "Model Predictive based load frequency control studies in a deregulated environment," Ph.D. Thesis, The University of Sheffield.

[16] H. Golpira, H. Bevrani and H. Golpira, "Application of GA Optimization for Automatic Generation Control Design in an Interconnected Power System," Energy Conversion and Management, vol. 52, pp. 2247-2255, January 2011. https://dx.doi.org/10.1016/j.enconman.2011.01.010

[17] H. Golpîra, H. Bevrani and H. Golpîra, "Effect of Physical Constraints on the AGC Dynamic Behaviour in an Interconnected Power System," International Journal on Advanced Mechatronic Systems, Vol. 3, No. 2, pp.79-87, July 2011.

[18] A. N. Gundes and L. Chow, "Controller Synthesis for Single-area and Multi-area Power Systems with Communication Delays," American Control Conference (ACC) Washington, DC, USA, vol. 14, pp. 970-975, June 3013.

[19] A. Gupta, Y. P. Verma and A. Chauhan, "Effect of Physical Constraints on Load Frequency Control of Deregulated Hybrid Power System Integrated with DFIG Wind Turbine," International Journal of Engineering and Technology (IJET), vol. 6 no. 6, pp. 2629-2640, January 2015.

[20] C. Huang, D. Yue, X. Xie and J. Xie, "Anti-Windup Load Frequency Controller Design for Multi-Area Power System with Generation Rate Constraint,” Energies, vol. 9, pp. 1-18, April 2016.

[21] S. Jian and V. Y. Hote, "PID Controller Design for Load Frequency Control: Past, Present and Future Challenges," 3rd IFAC Conference on Advances in Proportional Integral-Derivative Control, Ghent, Belgium, vol. 2, pp. 604-609, May 2018 https://dx.doi.org/10.3390/en9050330

[22] A. Khodabakhshian and M. Edrisi, "A New Robust PID Load Frequency Controller," Control Engineering Practice, vol. 16, pp. 1069-1080, March 2008 https://dx.doi.org/10.1016/j.conengprac.2007.12.003

[23] G. Kou, P. Markham, S. Hadley, T. King and Y. Liu, "Impact of Governor Dead Band on Frequency Response of the U.S. Eastern Interconnection," IEEE Transactions on Smart Grid, vol. 12, pp. 110, April 2015. https://dx.doi.org/10.1109/TSG.2015.2435258

[24] S. R. Krishna, P. Singh and M. S. Das, "Control of Load Frequency of Power System by PID Controller Using PSO," International Journal of Recent Development in Engineering and Technology, vol. 5, no. 6, pp. 37-43, June 2016.

[25] M. S. Kumar and S.K.V Smitha, "Design of Tuning Methods for Fractional Order $\mathrm{PI}^{\lambda} \mathrm{D}^{\mu}$ Controller Using PSO Algorithm," International Journal for Research in Applied Science \& Engineering Technology (IJRASET). vol. 2, no. XII, pp. 436-442, December 2014

[26] S. Mirjalili, "The Ant Lion Optimization," Advances in Engineering Software, vol. 83, pp. 80-98, March 2015. https://dx.doi.org/10.1016/j.advengsoft.2015.01.010

[27] D. K. Mishra, A. Mohanty and P. Ray, "Multi-area Automatic Generation Control with FOPID and TID Controller," International Journal of Control Theory and Application vol. 10, no. 6, pp. 397 410, July 2017.

[28] Y. Mobarak, "Effects of the Droop Speed Governor and Automatic Generation Control AGC on Generator Load Sharing of Power System," International Journal of Applied Power Engineering (IJAPE), vol. 4, no. 2, pp. 84-95, August 2015. http://iaesjournal.com/online/index.php/IJAPE

[29] J. Morsali, K. Zare and M. T. Hagh, "Appropriate Generation Rate Constraint (GRC) Modeling Method for Reheat Thermal Units to Obtain Optimal Load Frequency Controller (LFC)," The 5th Conference on Thermal Power Plants (IPGC) Shahid Beheshti University, Tehran, Iran, vol. 8, pp. 29-34, June 2014 https://dx.doi.org/10.1109/CTPP.2014.7040611

[30] P. G. Naidu and R. G. Rao, "Load Frequency Control for Two-area Interconnected Power System by Using Sliding Mode Controller," International Journal of Electrical, Electronics and Data Communication, vol. 4, Issue-10, pp. 11-18, October 2016.
[31] M. Ozkop, I. H. Altas, and A. M. Sharaf, "Load Frequency Control in Four Area Power Systems Using Fuzzy Logic PI Controller," 16th National Power Systems Conference, vol. 1, pp. 233-240, December 2010.

[32] I. Pan and S. Das, "Fractional-order load-frequency control of interconnected power systems using chaotic multi-objective optimization," Applied and Soft Computing Journal, vol. 67, pp. 1-17, January 2015. http://dx.doi.org/10.1016/j.asoc.2014.12.032

[33] D. G. Padhan and S. Majhi, "A New Control Scheme for PID Load Frequency Controller of Single-area and Multi-area Power Systems," ISA Transactions vol. 52, pp. 242-251, January 2013. http://dx.doi.org/10.1016/j.isatra.2012.10.003

[34] S. Prakash and S. K. Sinha, "Intelligent PI Control Technique in Four Area Load Frequency Control of Interconnected Hydro-thermal Power System," 2012 International Conference on Computing, Electronics and Electrical Technologies [ICCEET], vol. 2, pp. 145-150, August 2012.

[35] R. Satheeshkumar and R. Shivakumar, "Ant Lion Optimization Approach for Load Frequency Control of Multi-Area Interconnected Power Systems," Circuits and Systems, vol. 7, pp. 2357-2383. July 2016. https://dx.doi.org/10.4236/cs.2016.79206

[36] H. A. Shayanfar, H. Shayeghi and A. Molaee, "Multi-Source Power System LFC Using the Fractional Order PID Controller Based on SSO Algorithm Including Redox Flow Batteries and SMES,” International Conference on Artificial Intelligence, vol. 4, pp. 300-306, April 2016.

[37] V. P. Singh, N. Kishor and P. Samuel, "Communication Time Delay Estimation for Load Frequency Control in Two-area Power System," Ad Hoc Networks. vol. 000, pp. 1-17, October 2015. https://dx.doi.org/10.1016/j.adhoc.2015.10.010

[38] T. Aleksei, E. Petlenkov \& J. Belikov, "FOMCON: a MATLAB Toolbox for Fractional-order System Identification and Control," International Journal of Microelectronics and Computer Science, vol. 2, no. 2, pp. 51-62, October 2011.

[39] S. Sondhi and Y. V. Hote, "Fractional Order PID Controller for Load Frequency Control," Energy Conversion and Management, vol. 85, pp. 343-353, March 2014 https://dx.doi.org/10.1016/j.enconman.2014.05.091.

[40] B. Sonker, D. Kumar, and P. Samuel, "A Modified Two-degree of Freedom Internal Model Control Configuration for Load Frequency Control of a Single Area Power System," Turkish Journal of Electrical Engineering \& Computer Sciences, vol. 25, pp. 4624-4635, March 2017. https://dx.doi.org/10.3906/elk-1701-225.

[41] W. Tan, "Tuning of PID Load Frequency Controller for Power Systems," International Journal Energy Conversion and Management vol. 50, pp. 1465-1472, April 2009 . https://dx.doi.org/10.1016/j.enconman.2009.02.024

[42] W. Tan, "Unified Tuning of PID Load Frequency Controller for Power Systems via IMC," IEEE Transactions on Power Systems, vol. 25, no. $1, \quad$ pp. $341-350, \quad$ February 2010. https://dx.doi.org/10.1109/TPWRS.2009.2036463

[43] W. Tan, "Decentralized Load Frequency Controller Analysis and Tuning for Multi-area Power Systems," Energy Conversion and Management, vol. 52, pp. 2015-2023, January 2011. https://dx.doi.org/10.1016/j.enconman.2010.12.011

[44] W. Tan, Y. Hao and D. Li D, "Load Frequency Control in Deregulated Environments via Active Disturbance Rejection," Electrical Power and Energy Systems, vol. 66, pp. 166-177, January 2015. https://dx.doi.org/10.1016/j.ijepes.2014.10.036

[45] W. Tan, S. Chang and R. Zhou, "Load Frequency Control of Power Systems with Non-linearities," Institute of Engineering and Technology Generation Transmission and Distribution, vol. 11, pp. 4307-4313, October 2017. https://dx.doi.org/10.1049/iet-gtd.2017.0599

[46] J. M. Thangaiah, and R. Parthasarathy, "Delay-dependent Stability Analysis of Power System Considering Communication Delays," International Transaction on Electrical Energy System, vol. 20, pp. 113, July 2016. https://dx.doi.org/10.1002/etep.2260

[47] A. Zamani, S. M. Barakati and S. Yousofi-Darmain, "Design of a Fractional Order PID Controller Using GBMO Algorithm for LoadFrequency Control with Governor Saturation Consideration," ISA Transactions, vol. 45, pp. 1-11, April 2016. https://dx.doi.org/10.1016/j.isatra.2016.04.021. 